\title{
Alocação de tempo em trabalho pelas mulheres brasileiras
}

\author{
Vívian dos Santos Queiroz \\ Professora - Universidade Federal do Rio Grande (FURG) \\ Endereço: Av. Itália, km 8 - Bairro Correios - Rio Grande/RS - Brasil \\ CEP: 96203-900 - E-mail: viviansq13@gmail.com
}

\section{Jorge Alberto Orellana Aragón}

Doutor em Economia - Universidade Federal do Rio Grande do Sul (UFRGS)

Endereço: Av. João Pessoa, 52 - Sala 33 B, $3^{\circ}$ andar - Porto Alegre/RS - Brasil

CEP: 90040-000 - E-mail: jorgealbertoorellana@gmail.com

Recebido em 14 de setembro de 2013. Aceito em 12 de junho de 2015.

\section{Resumo}

Este artigo investiga a alocação de horas de trabalho pelas mulheres brasileiras usando dados da PNAD de 2011. Para tanto, são utilizadas duas estratégias empíricas: modelos heckit e double hurdle, que permitem a estimação conjunta da participação da muIner na força de trabalho e quantidade de horas de trabalho. Os principais resultados indicam que o ciclo de vida, como casamento, maternidade e construção da família reduzem a oferta de trabalho das mulheres. Entretanto, a educação, condição de chefe de família e acesso a creches colaboram para aumentar a inserção feminina no mercado de trabalho. Já a renda do esposo apresenta efeito negativo sobre a decisão de trabalho da mulher. Portanto, para estimular a entrada das mulheres no mercado de trabalho, as políticas públicas devem ser formuladas visando aumentar o investimento em educação da mulher e ampliar a oferta de creches como forma de dar suporte ao cuidado das crianças na primeira infância.

\section{Palavras-Chave}

Oferta de trabalho feminina. Horas de trabalho. Família. Modelo heckit. Modelo double hurdle.

\begin{abstract}
This article investigates the working hours of women in the Brazilian labor market using data from Pesquisa Nacional por Amostra de Domicílio (National Household Survey) or PNAD of 2011. A heckit model and double hurdle model are used to estimate the women's participation in the workforce and hours worked. The main results indicate that marriage and motherhood reduce the women labor supply. However, education, head of household and access to childcare collaborate to raise female participation in the labor force. Spouse's income collaborates to reduce female participation in the workforce. Finally, to encourage the entry of women into the labor market, the public policies should be directed to increase the investment in women's education and in the childcare supply.
\end{abstract}




\section{Keywords}

Women's participation. Working hours. Family. Heckit model. Double hurdle model.

\section{JEL Classification}

J01. J13. J22.

\section{Introdução}

A partir da década de 70, a mulher começa a se inserir no mercado de trabalho mais intensamente devido tanto ao processo acelerado de industrialização e urbanização, quanto por mudanças culturais e sociais relacionadas com o seu papel na sociedade. A tendência crescente da participação feminina na força de trabalho continua até dias atuais. Entretanto, várias mudanças no perfil das trabalhadoras acompanharam esse aumento de participação e estão relacionadas ao perfil etário, ao estado civil e à escolaridade. Por exemplo, no Brasil, a taxa de participação das mulheres casadas com 16 anos de idade ou mais no mercado de trabalho passou de $28,7 \%$ para $36,9 \%$ entre 1970 e 1980 (Ramos; Soares, 1995). Em um período mais recente, de 2001 a 2005, a taxa de atividade entre mulheres com 15 e 64 anos de idade passou de 58\% para 63\% (Ramos et al., 2011). No princípio, as mulheres eram muito jovens, solteiras e pouco escolarizadas e, posteriormente, observou-se elevada participação no mercado de trabalho de mulheres acima de 25 anos, casadas ou chefes de família, com níveis elevados de escolaridade e auferindo níveis mais elevados de renda (Hoffmann; Leone, 2004).

A rápida transição demográfica pela qual vem passando o país tem colaborado para a mudança na estrutura familiar. A taxa de fecundidade, que era de 6,3 em 1960, passou para 1,94 filhos em 2009. ${ }^{l}$ Com mais tempo livre, as mulheres podem participar mais do mercado de trabalho e colaborar para a geração de renda familiar (Ramos; Soares, 1995). Desse modo, a participação feminina no mercado de trabalho pode ajudar às respectivas famílias a saírem da condição de pobreza (Ramos et al., 2011). Muitas mulheres têm postergado a maternidade em busca de mais segurança profissional e financeira. Além disso, a escolaridade feminina aumentou progressivamente, fato que também pode estar influenciando esse comportamento devido ao tempo dedicado à qualificação. Conforme dados

\footnotetext{
${ }^{1}$ Segundo o Ministério da Previdência Social (2011).
} 
da Pesquisa Nacional por Amostra de Domicílios (PNAD) de 2011, mais de 39\% das mulheres com idade acima de 30 anos tiveram filhos. Essa taxa sobe para cerca de $62 \%$ quando as mulheres são mais escolarizadas (12 ou mais anos de estudo).

Embora a participação feminina na força de trabalho tenha se elevado, a mulher ainda enfrenta dupla jornada, ou seja, tem que dividir seu tempo com jornada de trabalho e afazeres domésticos, os quais, geralmente, são atribuídos às mulheres. Assim, elas geralmente se inserem em ocupações com menores jornadas de trabalho e têm mais dificuldade de ascender a determinados postos de trabalho que exigem mais horas trabalhadas e tal situação acaba se transformando em barreira para a ascensão feminina no trabalho (Costa, 2007; Fontoura; Gonzalez, 2009).

Nesse sentido, a alocação de tempo feminina entre as atividades domésticas e trabalho tem sofrido grandes transformações econômicas e sociais nos últimos anos. Segundo Aguiar e Hurst (2007), elas passaram a participar mais no mercado de trabalho e dedicam menos tempo em casa do que antes e, de acordo com Mulligan e Rubinstein (2008), seu tempo no mercado foi transformado com frações crescentes de trabalho em ocupações que eram consideradas especialmente masculinas.

Portanto, o objetivo desse trabalho é investigar os determinantes da participação e alocação de horas de trabalho pelas mulheres no mercado de trabalho brasileiro utilizando dados da PNAD de 2011. Para tanto, dois modelos são propostos: (i) um modelo de dois estágios de Heckman (1979), conhecido como heckit, para as decisões de participação no mercado de trabalho e alocação de horas de trabalho e (ii) um modelo double hurdle, que estima conjuntamente as respectivas decisões. Esta pesquisa ganha destaque uma vez que na literatura brasileira há escassez de estudos que tratem a questão da participação feminina a partir do enfoque da alocação de tempo em trabalho e as informações produzidas fornecerão elementos importantes para a formulação de políticas públicas visando melhorar a inserção e o bem-estar das mulheres no mercado de trabalho brasileiro.

Este trabalho encontra-se divido em sete partes incluindo esta introdução. A segunda parte apresenta alguns aspectos importantes da participação feminina no mercado de trabalho. A terceira parte 
discute o referencial teórico da oferta de trabalho feminina. A quarta parte apresenta a estratégica empírica adotada e a quinta parte discute a base de dados e seus tratamentos. A sexta parte expõe e discute os resultados e, por fim, a última parte é reservada para as considerações finais.

\section{Aspectos da participação da mulher no mercado de trabalho}

Entre 1980 e 2009, a taxa de atividade feminina mundial cresceu de aproximadamente de $50 \%$ para cerca de $52 \%$, enquanto que a taxa masculina caiu de $82 \%$ para $78 \%$, de acordo com dados do International Labor Organization (ILO) (2012).

A Figura 1 ilustra a participação de mulheres com idade a partir de 15 anos no mercado de trabalho, segundo estimações do ILO para 2012. É possível ver que o Brasil registrou uma taxa de participação feminina (em torno de 60\%) superior à exibida por países mais avançados como Estados Unidos (57\%) e vários outros países europeus.

Segundo a ILO, as diferenças entre as taxas de participação femininas regionais foram se reduzindo, e países que registraram baixas taxas de atividade anteriormente experimentaram grande crescimento, como vários países da América Latina e Norte da África. Outros países que possuíam altas taxas e atividade se depararam com declínio da participação feminina, como é o caso de alguns países da Europa. ${ }^{2}$ O desenvolvimento econômico mundial que se seguiu nas últimas décadas pode ter contribuído para a ampliação das oportunidades de trabalho para mulheres.

2 Estudo comparando as taxas de participação feminina entre 1980 e 2009. 


\section{ALOCAÇÃO DE TEMPO EM TRABALHO PELAS MULHERES BRASILEIRAS}

Arquivo suplementar de tabelas e gráficos:

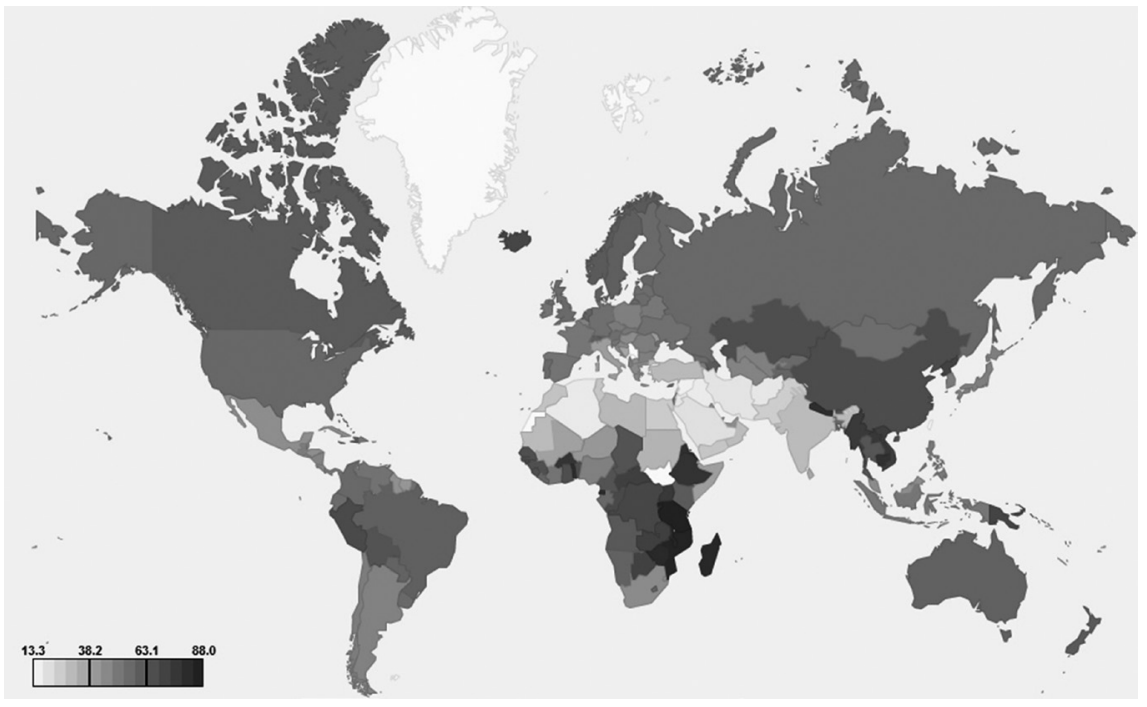

Figura 1 - Taxa de participação feminina na força de trabalho para grupo com 15 anos ou mais de idade (2012)

Fonte: International Labor Organization (2012).

Nota: Os espaços em branco se referem aos dados não disponíveis.

No Brasil, a Figura 2 mostra a taxa de participação por gênero entre 1995 e 2011. Vê-se que apesar de as mulheres experimentarem um crescimento da taxa de atividade entre 1995 e 2005, ela ainda é bastante inferior à dos homens. Fontoura e Gonzalez (2009) sugerem que pode estar havendo uma defasagem entre o aumento da participação feminina e a criação de novos postos de trabalhos, além disso, as mulheres podem estar sofrendo com os efeitos da discriminação por gênero e da dupla jornada de trabalho que podem impedi-las de se inserirem em certas ocupações. ${ }^{3}$ Além do mais, a renda do esposo também pode colaborar para reduzir a participação da mulher no mercado de trabalho brasileiro (Sedlacek; Santos, 1991; Schmitt; Ribeiro, 2004).

3 A dupla jornada se refere às responsabilidades domésticas, que geralmente são atribuídas às mulheres, e a jornada que executa no mercado de trabalho. 
Costa (2007) acrescenta que a mulher se deparou com novas oportunidades de trabalho que podem ter contribuído para a inserção feminina no mercado de trabalho, tais como a industrialização crescente de bens e serviços que eram anteriormente produzidos pelas famílias (tais como alimentos, cuidados com crianças ou pessoas velhas e doentes na família) e podem ter causado evidente redução da fecundidade, bem como o avanço da urbanização.

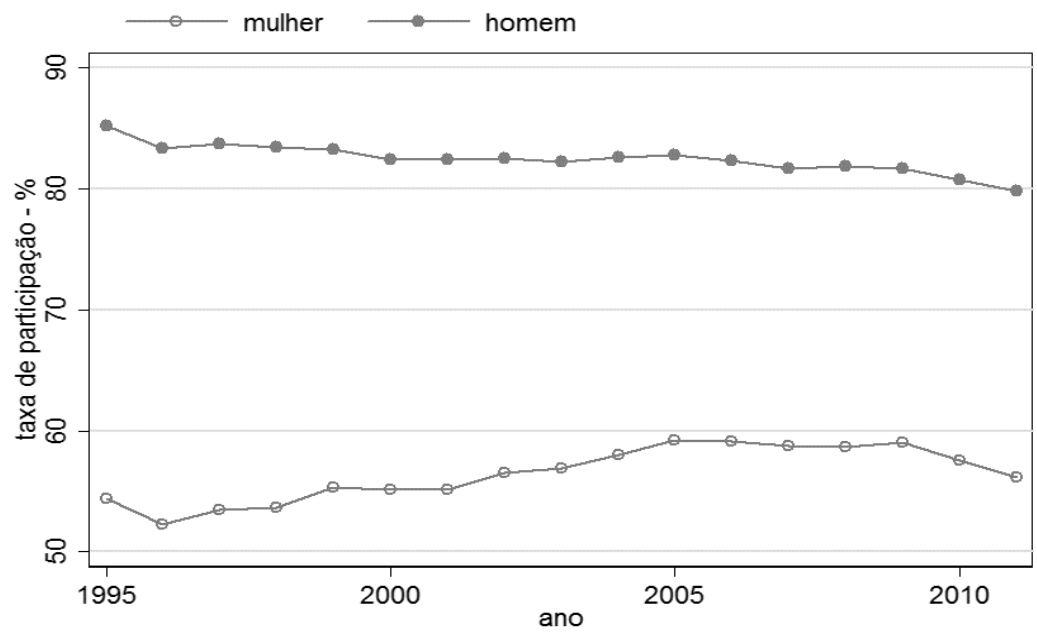

Figura 2 - Brasil - Taxa de participação no mercado de trabalho por gênero (1995 - 2011)

Fonte: Elaborado pelos autores a partir de dados da PNADs.

Nota: Valores do ano de 2000 e 2010 foram obtidos por interpolação. Valores expandidos para o universo.

A partir da Figura 3 é possível perceber que as mulheres trabalham em média menos horas que os homens e que as taxas mais elevadas são observadas na idade produtiva tanto para homens quanto mulheres. Ademais, é necessário chamar atenção para o fato de que as mulheres possuem um ciclo de vida diferente dos homens, como a fase da maternidade que geralmente demanda mais tempo e dedicação e afeta, consequentemente, a inserção feminina no mercado de trabalho. 


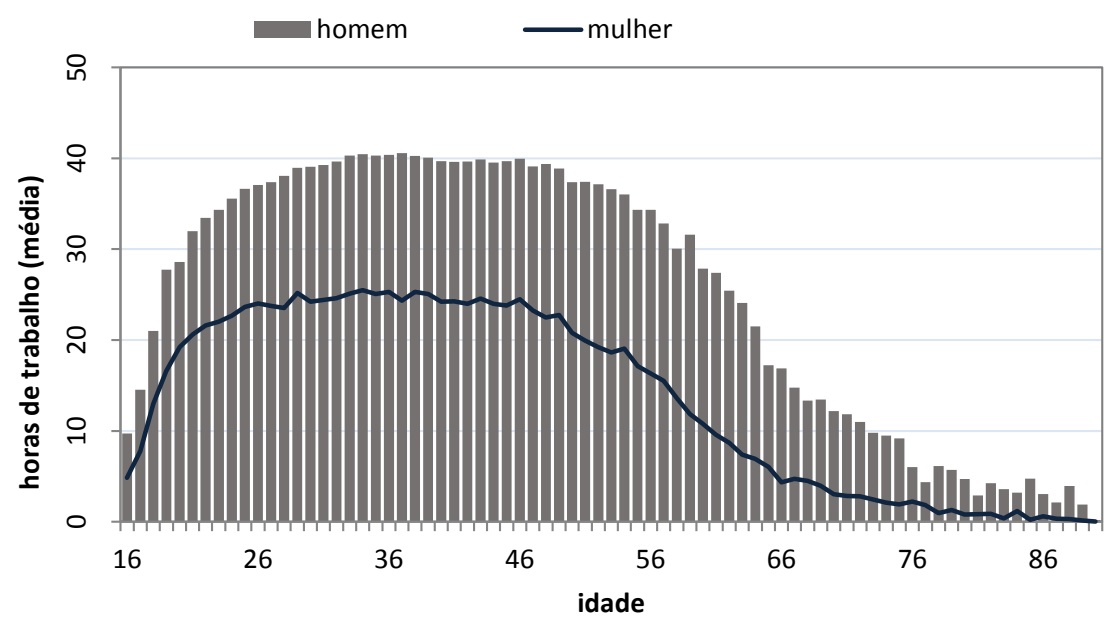

Figura 3 - Brasil - horas médias de trabalho semanal por gênero (2011)

Fonte: Elaborado pelos autores a partir dos dados da PNAD de 2011.

Nota: Valores expandidos para o universo.

Quanto à importância da família, a Tabela 1 mostra que as mulheres não casadas trabalham em média mais horas por semana do que as casadas, especialmente até a faixa de idade de 37 e 46 anos de idade (diferença de 2,5h). Isto pode estar indicando que as primeiras têm menos responsabilidades domésticas do que as últimas, como cuidar dos filhos e dar mais assistência ao marido. Também se verifica que as mulheres casadas com até 36 anos de idade que possuem filhos menores de 14 anos de idade trabalham menos $3 \mathrm{~h}$ por semana em média quando comparadas com as mulheres casadas sem filhos. Esse resultado pode estar sugerindo que as mulheres que possuem filhos menores de 14 anos dedicam-se mais às atividades domésticas, tendendo a reduzir sua participação no mercado de trabalho. 
Tabela 1 - Brasil - Horas médias de trabalho semanal das mulheres casadas e solteiras, com e sem filhos menores por faixas de idade (2011)

\begin{tabular}{l|ccc|ccc}
\hline $\begin{array}{l}\text { Faixas de } \\
\text { idade }\end{array}$ & $\begin{array}{c}\text { casada } \\
(1)\end{array}$ & $\begin{array}{c}\text { solteira } \\
(2)\end{array}$ & $\begin{array}{c}\text { diferença } \\
(1)-(2)\end{array}$ & $\begin{array}{c}\text { casada com filho } \\
\text { menor de 14 anos } \\
(3)\end{array}$ & $\begin{array}{c}\text { casada sem filho } \\
(4)\end{array}$ & $\begin{array}{c}\text { diferença } \\
(3)-(4)\end{array}$ \\
\hline $16-26$ & 37,2 & 37,7 & $-0,5$ & 35,9 & 39,5 & $-3,6$ \\
& $(13,1)$ & $(12,3)$ & & $(13,6)$ & $(11,4)$ & \\
$27-36$ & 37,1 & 38,8 & $-1,7$ & 36,5 & 39,6 & $-3,1$ \\
& $(13,2)$ & $(12,1)$ & & $(13,6)$ & $(11,3)$ & \\
$37-46$ & 36,4 & 39,0 & $-2,5$ & 35,7 & 38,1 & $-2,4$ \\
& $(13,5)$ & $(12,8)$ & & $(13,4)$ & $(13,4)$ & \\
$47-56$ & 35,5 & 37,3 & $-1,8$ & 35,6 & 35,4 & 0,1 \\
& $(14,3)$ & $(13,8)$ & & $(13,9)$ & $(15,0)$ & \\
$57-66$ & 32,4 & 34,5 & $-2,2$ & 34,4 & 32,2 & 2,2 \\
& $(15,1)$ & $(15,6)$ & & $(16,5)$ & $(15,4)$ & \\
$67-76$ & 26,2 & 29,2 & $-3,0$ & 29,6 & 26,1 & 3,4 \\
& $(16,0)$ & $(16,3)$ & & $(15,0)$ & $(16,8)$ & \\
$77-86$ & 24,0 & 24,1 & $-0,1$ & 10,0 & 23,1 & $-13,1$ \\
& $(13,3)$ & $(16,6)$ & $-3,1$ & $(0,0)$ & $(14,5)$ & $-18,0$ \\
87 ou mais & 24,7 & 28,1 & $-3,4$ & 12,8 & 30,8 & $(13,3)$ \\
& $(15,2)$ & $(15,5)$ & & $(5,0)$ & & \\
\hline
\end{tabular}

Fonte: Elaborado pelos autores a partir dos dados da PNAD de 2011.

Nota: Desvios-padrões entre parênteses. Valores expandidos para o universo.

A partir da Tabela 2 é possível observar que quanto maior o rendimento domiciliar per capita em salário mínimo (SM), menor é a predisposição do trabalhador de ambos os gêneros de abrir mão de lazer por mais horas de trabalho (colunas 1 e 4). Note-se que, em geral, as mulheres em qualquer condição trabalham menos horas por semana quando comparadas com os homens.

As horas de trabalho semanais das mulheres casadas com filhos menores de 14 anos aumentam até os 2 SM de renda domiciliar per capita, enquanto que as horas trabalhadas das casadas são crescentes até os $3 \mathrm{SM}$. Desse modo, as mulheres casadas com filhos menores podem ser mais predispostas a abdicar de horas de trabalho para cuidar dos filhos. As mulheres casadas e casadas com filhos menores de 14 anos que auferem até $1 / 2$ SM de renda domiciliar per capita trabalham em média menos horas por semana quando se compara com o total de horas de trabalho (colunas 1, 2 e 3). Segundo Ramos et al. (2011), as mulheres de famílias mais pobres tendem a participar menos do mercado de trabalho pela falta de acesso a creches ou recursos financeiros para arcar com os custos de uma babá e, portanto, acabam se dedicando mais à lida doméstica e cuidado com os filhos menores. 
Tabela 2 - Brasil - Horas médias de trabalho semanal por gênero e renda domiciliar em faixas de salário mínimo para idade entre 16 e 90 anos (2011)

\begin{tabular}{|c|c|c|c|c|c|c|}
\hline \multirow[b]{2}{*}{$\begin{array}{l}\text { faixas de salários } \\
\text { mínimos (SM) }\end{array}$} & \multicolumn{3}{|c|}{ Mulheres } & \multicolumn{3}{|c|}{ Homens } \\
\hline & $\begin{array}{c}\text { horas } \\
\text { trabalhadas } \\
\text { total } \\
(1)\end{array}$ & $\begin{array}{c}\text { casada } \\
(2)\end{array}$ & $\begin{array}{l}\text { casada } \\
\text { com } \\
\text { filhos } \\
\text { menores } \\
\text { de } 14 \\
\text { anos (3) }\end{array}$ & $\begin{array}{c}\text { horas } \\
\text { trabalhadas } \\
\text { total } \\
(4)\end{array}$ & $\begin{array}{l}\text { casado } \\
(5)\end{array}$ & $\begin{array}{l}\text { casado } \\
\text { com } \\
\text { filhos } \\
\text { menores } \\
\text { de } 14 \\
\text { anos }(6) \\
\end{array}$ \\
\hline até $1 / 4 \mathrm{SM}$ & $\begin{array}{c}27,9 \\
(14,7)\end{array}$ & $\begin{array}{c}26,6 \\
(13,8)\end{array}$ & $\begin{array}{c}26,4 \\
(13,6)\end{array}$ & $\begin{array}{c}38,4 \\
(13,5)\end{array}$ & $\begin{array}{c}39,7 \\
(13,1)\end{array}$ & $\begin{array}{c}39,0 \\
(13,4)\end{array}$ \\
\hline mais de $1 / 4$ até $1 / 2 \mathrm{SM}$ & $\begin{array}{c}33,0 \\
(15,2)\end{array}$ & $\begin{array}{c}30,6 \\
(15,2)\end{array}$ & $\begin{array}{c}31,0 \\
(15,2)\end{array}$ & $\begin{array}{c}41,9 \\
(12,7)\end{array}$ & $\begin{array}{c}43,2 \\
(12,3)\end{array}$ & $\begin{array}{c}43,2 \\
(12,1)\end{array}$ \\
\hline mais de $1 / 2$ até $1 \mathrm{SM}$ & $\begin{array}{c}36,5 \\
(13,7)\end{array}$ & $\begin{array}{c}35,5 \\
(14,1)\end{array}$ & $\begin{array}{c}36,8 \\
(13,3)\end{array}$ & $\begin{array}{c}42,9 \\
(11,7)\end{array}$ & $\begin{array}{c}43,9 \\
(11,7)\end{array}$ & $\begin{array}{c}44,3 \\
(11,0)\end{array}$ \\
\hline mais de 1 até $2 \mathrm{SM}$ & $\begin{array}{c}38,4 \\
(12,6)\end{array}$ & $\begin{array}{c}38,0 \\
(12,9)\end{array}$ & $\begin{array}{c}38,6 \\
(12,3)\end{array}$ & $\begin{array}{c}43,5 \\
(11,5)\end{array}$ & $\begin{array}{c}44,5 \\
(11,9)\end{array}$ & $\begin{array}{c}44,8 \\
(11,9)\end{array}$ \\
\hline mais de 2 até $3 \mathrm{SM}$ & $\begin{array}{c}38,7 \\
(12,1)\end{array}$ & $\begin{array}{c}38,9 \\
(12,5)\end{array}$ & $\begin{array}{c}38,6 \\
(12,1)\end{array}$ & $\begin{array}{c}43,3 \\
(11,8)\end{array}$ & $\begin{array}{c}44,3 \\
(12,2)\end{array}$ & $\begin{array}{c}44,1 \\
(12,3)\end{array}$ \\
\hline mais de 3 até $5 \mathrm{SM}$ & $\begin{array}{c}37,9 \\
(12,2)\end{array}$ & $\begin{array}{c}38,1 \\
(12,4)\end{array}$ & $\begin{array}{c}37,3 \\
(12,0)\end{array}$ & $\begin{array}{c}42,8 \\
(12,2)\end{array}$ & $\begin{array}{c}43,6 \\
(12,3)\end{array}$ & $\begin{array}{c}43,7 \\
(11,8)\end{array}$ \\
\hline mais de $5 \mathrm{SM}$ & $\begin{array}{c}37,5 \\
(12,1)\end{array}$ & $\begin{array}{c}37,6 \\
(11,9)\end{array}$ & $\begin{array}{c}36,6 \\
(11,5)\end{array}$ & $\begin{array}{c}42,1 \\
(12,9)\end{array}$ & $\begin{array}{c}42,7 \\
(13,0)\end{array}$ & $\begin{array}{c}43,5 \\
(12,8)\end{array}$ \\
\hline
\end{tabular}

Fonte: Elaborado pelos autores a partir dos dados da PNAD de 2011.

Nota: Desvios-padrões entre parênteses. Valores expandidos para o universo.

Por fim, foi possível observar um avanço na participação das mulheres no mercado de trabalho brasileiro ao longo do tempo, embora essa participação ainda possa ser considerada inferior à masculina. No passado, a força de trabalho feminina foi considerada suplementar a do homem, isto é, elas se mantinham afastadas do mercado de trabalho para somente ingressar em momentos de recessão para complementar a renda domiciliar. As transformações econômicas e sociais que têm ocorrido nos últimos tempos têm favorecido mudanças no perfil da população economicamente ativa, com considerável participação da mulher. Entretanto, vários são os fatores que podem afetar de forma decisiva a decisão de participação da mulher no mercado de trabalho, sobretudo o estudo, casamento, maternidade e renda domiciliar. Tais responsabilidades podem afetar a alocação de tempo em trabalho por parte da mulher de forma distinta ao longo do seu ciclo de vida. 


\section{Referencial teórico}

O modelo neoclássico de escolha entre lazer e trabalho explica os fatores que levam o indivíduo a trabalhar e, consequentemente, a decidir quantas horas de trabalho ofertar (Borjas, 1996). O indivíduo obtém satisfação com o consumo de bens $C$ e de lazer $L$ e, a partir desses fatores, a satisfação individual pode ser mensurada pela função de utilidade $U$ que torna a pessoa mais satisfeita quanto maior for $U$ (Borjas, 1996). Dessa forma, o trabalhador decide ofertar trabalho através da maximização de sua utilidade, que é uma função da quantidade de bens $\mathrm{C}$ e da quantidade de tempo gasto em atividades de lazer $L$.

A maximização da utilidade do trabalhador está sujeita a uma restrição orçamentária que depende da renda do não trabalho $V$, do número de horas trabalhadas $h$ e da taxa de salário-hora $w$. Portanto, o problema de maximização da utilidade do trabalhador pode ser definido da seguinte forma (Borjas, 1996):

$$
\begin{gathered}
\text { Max } U(C, L) \\
\text { sujeito a } \\
C=w h+V
\end{gathered}
$$

O consumo ou gastos com bens é igual à soma da renda oriunda do trabalho $w$ h e da renda do não trabalho $V$. O tempo total alocado no trabalho e no lazer é o tempo total disponível no período, ou seja, $T$ horas por semana que pode ser definido como $T=h+L$.

A condição de primeira ordem do problema de maximização pode ser dada da seguinte forma (Borjas, 1996):

$$
\frac{\partial U / \partial L}{\partial U / \partial C}=T M S=w
$$

A razão das utilidades marginais ou taxa marginal de substituição (TMS) é igual à taxa de salário-hora que são, respectivamente, as inclinações da curva de indiferença e da restrição orçamentária. No ponto de tangência entre a curva de indiferença e a restrição orçamentária se determinam o número de horas trabalhadas e a 
quantidade de bens que é consumida. Esse tipo de solução somente é obtido quando se tem uma solução interior onde $L<T$ e $H>0$ (Scorzafave; Menezes-Filho, 2001).

Segundo Scorzafave e Menezes-Filho (2001), a taxa marginal de substituição entre consumo e lazer, TMS, pode ser entendida como o salário reserva do trabalhador, ou seja, o salário que ele exige para sair da inatividade ou para abrir mão de uma hora de lazer quando não está trabalhando. Para tanto, tem que ser considerada a solução de canto que permite que a curva de indiferença toque a restrição orçamentária em um ponto onde $L=T$ e $H=0$ que significa que o trabalhador está disposto a ofertar zero horas de trabalho à taxa de salário vigente. Assim sendo, para a mulher decidir participar da força de trabalho, o salário hora de mercado deve ser maior que o seu salário de reserva .

Segundo Mincer (1962), um aumento na taxa de salário real torna mais caro o tempo de lazer e tende a provocar um aumento nas horas de trabalho. No entanto, para uma determinada quantidade de horas trabalhadas, um aumento na taxa de salário constitui um aumento na renda, o que leva a um aumento nas compras de diversas mercadorias, incluindo o tempo de lazer. Assim, as horas de trabalho tendem a diminuir.

Muitos estudos têm tratado de analisar a participação das mulheres no mercado de trabalho destacando como principais fatores determinantes dessa atividade o aumento dos salários das mulheres, custo de vida, disponibilidade de empregos adequados, idade, grau de educação, experiência no mercado de trabalho, filhos menores, condição da família, acesso a creches para filhos pequenos e rendimento familiar. A oferta de trabalho feminina tende a aumentar com a idade, porém o aumento ocorre a taxas decrescentes (Leme; Wajnman, 1999; Martins, 2001). A decisão de trabalho delas é afetada sobretudo pelo ciclo de vida, como a fase do casamento, da maternidade e da construção da família.

A queda da taxa de fecundidade registrada nos últimos anos está relacionada com o incremento da participação feminina no mercado de trabalho (Psacharopoulos; Tzannatos, 1992; Leme; Wajnman, 1999). Todavia, no período reprodutivo, a mulher reduz consideravelmente sua participação na força de trabalho em virtude do cui- 
dado com os filhos pequenos (Gonzaga et al. 2003; Birch, 2005; Ramos et al., 2011). ${ }^{4}$ Quanto mais numerosos forem os filhos, menor é a probabilidade de que as mulheres participem no mercado de trabalho, e essa situação se agrava com a condição social das mulheres (Sedlacek; Santos, 1991; Ramos et al., 2011). Psacharopoulos e Tzannatos (1992) observaram para a América Latina que a inserção feminina na força de trabalho cai de $3 \%$ a $5 \%$ para cada filho.

Quanto às mulheres casadas, a chance de trabalho é influenciada principalmente pela idade, escolaridade, número de filhos, salário, ocupação do esposo e outras fontes de renda (Kreps, 1971; Kreps; Clark, 1975). Segundo Psacharopoulos e Tzannatos (1992), a chance das mulheres solteiras participarem da força de trabalho é o dobro das casadas. Todavia, Wajnman e Rios-Neto (2000) chamaram atenção que as casadas tendem a permanecer no mercado de trabalho mesmo após o casamento se elas trabalhavam desde jovens. Ademais, as casadas ofertam mais trabalho quando possuem mais anos de estudo, declina a taxa de fecundidade e quando se encontram na condição chefes de família (Kreps, 1971; Kreps; Clark, 1975; Sedlacek; Santos, 1991; Psacharopoulos; Tzannatos, 1992).

A renda do esposo pode afetar a decisão de trabalho das mulheres casadas quando estas desempenham o papel de trabalhador adicional no domicílio, isto é, aumentam sua participação na força de trabalho quando diminui a renda familiar (Mroz, 1987; Sedlacek; Santos, 1991; Schmitt; Ribeiro, 2004; Birch, 2005; Cirino; Lima 2011). Além disso, Hoffmann e Leone (2004) e Kreps e Clark (1975) argumentaram que a oferta de trabalho feminina é reduzida quando há outras fontes de rendas que possam substituir a renda do trabalho.

A oferta de creches pode aumentar a participação feminina no mercado de trabalho por liberar tempo para elas se dedicarem mais ao trabalho (Costa, 2007; Ramos et al., 2011). As mulheres tendem a ter um salário de reserva maior do que os homens devido à necessidade de mais tempo para realizarem outras atividades relacionadas à lida doméstica, assim, são mais propensas a uma menor participação

4 A licença maternidade permite que as mães com bebês recém-nascidos tenham direito à uma licença remunerada de 120 dias com ausência do trabalho durante esse período. Após a licença maternidade, a mulher ainda tem direito a descansos especiais destinados à amamentação da criança durante a jornada de trabalho até que o filho complete 6 meses de idade. Consultar licença maternidade pelo Ministério do Trabalho e Emprego disponível em: http://portal. mte.gov.br/ouvidoria/licenca-maternidade.htm 
no mercado de trabalho (Becker, 1991; Aguiar; Hurst, 2007; Costa, 2007). A impossibilidade de a mulher arcar com os custos de um substituto para o tempo dedicado para os filhos menores pode levar a sua saída do mercado de trabalho, reforçando a necessidade de políticas públicas voltadas para aumentar a oferta de creches e contribuir com a redução da pobreza das famílias (Ramos et al., 2011).

As ocupações com jornadas de trabalho mais flexíveis colaboram para a inserção das mulheres no mercado de trabalho (Costa, 2007). As mulheres geralmente alocam menos horas de trabalho quando comparadas com os homens devido à dupla jornada que elas enfrentam. Muitas mulheres dedicam mais horas aos afazeres domésticos e este fato impacta diretamente no tipo de ocupação que a mulher tem acesso, nas remunerações e nas oportunidades de ascendência de cargo (Fontoura; Gonzalez, 2009).

A educação, por seu turno, é uma ferramenta essencial para aumentar a taxa de atividade das mulheres já que pode ampliar o acesso às melhores ocupações e aos mais altos salários (Martins, 2001; Costa, 2007; Cirino; Lima 2011). O acirramento da competição entre mulheres no mercado de trabalho pode estimular o investimento em capital humano e a entrada das mais qualificadas na força de trabalho (Mulligan; Rubinstein, 2008). Além do mais, são as mulheres mais pobres que mais se beneficiam com o aumento da escolaridade, pois registram maiores taxas de atividade com o aumento do grau de estudo (Costa, 2007).

Apesar do avanço da literatura para entender os fatores determinantes da participação feminina na força de trabalho, verificou-se que há uma lacuna na literatura brasileira com relação à investigação do tempo de trabalho alocado pelas mulheres na força de trabalho brasileira. Portanto, o presente trabalho ganha relevância por avançar essa questão.

\section{Estratégia empírica}

Nesta seção são apresentados os métodos de investigação usados para a identificação e análise dos determinantes da oferta de trabalho das mulheres e da quantidade de horas de trabalho alocadas. 
A análise poderia ser realizada por meio da estimação de dois modelos separados, ou seja, a primeira decisão seria a de participar ou não do mercado de trabalho que seria estimada por um probit, ao passo que a segunda decisão seria a quantidade de horas que a trabalhadora alocaria no trabalho que seria estimada a partir de um tobit. Entretanto, essa abordagem não permite captar os efeitos assimétricos das varáveis exógenas sobre as probabilidades de trabalho e horas de trabalho. Diante disso, este trabalho busca evitar essa restrição ao introduzir a estimação de tais decisões através dos modelos heckit e double hurdle, os quais admitem correlação entre os termos não observados das equações de participação no mercado de trabalho e horas trabalhadas. ${ }^{5}$

\subsection{Método heckit}

O método em dois estágios de Heckman (1979) propõe uma correção para o problema de viés de seleção causado pela estimação da subamostra censurada de horas de trabalho. O heckit considera que as decisões de trabalho e horas ofertadas de trabalho são decisões simultâneas e parece mais adequado ao estudo da oferta de trabalho feminina.

Supõe-se que uma variável de interesse, $y_{2}^{*}$, para as horas de trabalho alocadas só pode ser observada se $y_{2}^{*}>0$, isto é, se a trabalhadora ofertar horas de trabalho. Neste caso, a trabalhadora oferta determinadas horas de trabalho se participa do mercado de trabalho, então uma nova variável latente é introduzida, $y_{1}^{*}$, para a decisão de participação no mercado de trabalho, onde $y_{2}^{*}$ é observado se somente se $y_{1}^{*}>0$.

Segundo Cameron e Trivedi (2005), este modelo de seleção de amostra, heckit, consiste de duas etapas: a primeira é estimada por um modelo probit para a decisão de participação da mulher no mercado de trabalho (equação de participação $-y_{1}^{*}$ ); a segunda é estimada por um modelo tobit para a quantidade de horas de trabalho (equação de resultado $-y_{2}^{*}$ ):

5 Gronau (1977) e Heckman (1974) apresentaram modelos econométricos consistentes com a maximização da utilidade que levou a modelos Tobit, adicionando a complicação de que o salário oferecido não é observado para as mulheres que não trabalham. 


$$
\begin{array}{ll}
y_{1}^{*}=X_{1} \beta_{1}+e_{1}, & y_{1}=\left\{\begin{array}{l}
1 \text { se } y_{1}^{*}>0 \\
0 \text { se } y_{1}^{*} \leq 0
\end{array}\right. \\
y_{2}^{*}=X_{2} \beta_{2}+e_{2}, & y_{2}=\left\{\begin{array}{l}
y_{2}^{*} \text { se } y_{1}^{*}>0 \\
- \text { se } y_{1}^{*} \leq 0
\end{array}\right.
\end{array}
$$

Onde: $X_{1}$ e $X_{2}$ são vetores de variáveis explicativas que constam de atributos pessoais e familiares das mulheres que afetam os respectivos estágios de decisão, além de serem assumidas como não correlacionadas com seus respectivos termos de erros; $e_{1}$ e $e_{2}$ são termos de erros normalmente e identicamente distribuídos; $y_{1}$ é uma variável binária indicadora de participação no mercado de trabalho, assim, $y_{1}$ assume o valor 1 quando $y_{1}^{*}>0$ e zero caso contrário; $y_{2}$ é observada quando $y_{1}^{*}>0$, enquanto que $y_{2}$ não precisa assumir qualquer valor quando $y_{1}^{*} \leq 0$. Portanto, se a mulher decidir participar do mercado de trabalho $\left(y_{1}=1\right)$, ela está reportando uma quantidade positiva de horas de trabalho.

Após a estimação da Equação de participação (4) em primeira etapa, obtêm-se a taxa inversa de Mill que é inserida na Equação (5) de resultado tobit como regressor adicional para corrigir o viés de seleção na amostra: $\lambda_{1}=\frac{f(C)}{F(C)}$ para o caso de participar no mercado de trabalho $y_{1}=1$ e $\lambda_{0}=-\frac{f(C)}{1-F(C)}$ para o caso de não participação no mercado de trabalho $y_{1}=0$, onde, $C=X_{1} \hat{\beta}_{1}$ é a predição linear da equação (4); $f$ é a função de densidade normal padrão e $F$ a função normal de densidade acumulada.

O modelo de Heckman (1979) pressupõe que os termos de erros seguem uma distribuição bivariada normal, $\sigma_{12}$ onde é o coeficiente de correlação:

$$
\left(\begin{array}{l}
e_{1} \\
e_{2}
\end{array}\right) \sim N\left[\left(\begin{array}{l}
0 \\
0
\end{array}\right),\left(\begin{array}{cc}
1 & \sigma_{12} \\
\sigma_{12} & \sigma_{2}^{2}
\end{array}\right)\right]
$$

Onde: $\sigma_{1}^{2}=1$ é a variância do termo de erro da Equação de participação (4) que por simplificação é normalizado para a unidade; $\sigma_{2}^{2}$ é a variância da Equação de horas de trabalho (5); e a correlação entre os termos de erro pode ser obtida por $\rho=\sigma_{12} / \sigma_{2}$. Se $\sigma_{12}=0$ ou $\rho=0$ significa que as decisões são independentes e poderiam ser modeladas separadamente, mas se $\rho \neq 0$, há viés de seleção na 
amostra que necessita que ser considerado (Cameron, Trivedi, 2005). O modelo heckit (Equações 4 e 5) pode ser estimado conjuntamente por máxima verossimilhança.

\subsection{Método double hurdle}

Os modelos heckit e double hurdle são semelhantes, pois consideram a questão da seletividade na amostra e permitem usar diferentes variáveis explicativas nos dois estágios. No entanto, na segunda etapa do heckit as observações "zeros" não são incluídas, enquanto que o double hurdle considera a possibilidade destes valores "zeros" constarem na segunda etapa, uma vez que seriam decorrentes de fatores aleatórios não observados. Dessa forma, no modelo double hurdle os valores "zeros" participam de ambos os estágios de decisão.

O modelo double hurdle proposto por Cragg (1971) é uma alternativa ao modelo heckit e foi criado através da modificação do modelo tobit padrão para tratar o problema da presença de excesso de zeros nos dados. Trata-se de um método no qual o trabalhador enfrenta duas etapas para alocar horas de trabalho: (i) decide se entra ou não no mercado de trabalho e (ii) decide quantas horas de trabalho vai ofertar. Neste sentido, o modelo é especificado da seguinte forma:

$$
\begin{aligned}
& Y=y_{1} y_{2} \\
& y_{2}=\left\{\begin{array}{lll}
0 & \text { se } & y_{2}^{*} \leq 0 \\
y_{2}^{*} & \text { se } & y_{2}^{*}>0
\end{array}\right.
\end{aligned}
$$

Onde: $Y$ é as horas trabalhadas observadas efetivamente que é gerado pela interação entre a variável indicadora de participação $y_{1}$ e a indicadora de quantidade de horas trabalhadas $y_{2}$. Caso o índice de utilidade seja positivo $y_{2}^{*}>0$, a trabalhadora decide ofertar quantidade positiva de horas de trabalho e $y_{2}$ capta o valor efetivamente de horas alocadas no mercado de trabalho, caso contrário a variável indicadora será zero e não depende da decisão de participação no mercado de trabalho. Neste modelo, o nível de horas de trabalho positivamente observado é dado por uma variável $Y$ de interação, onde o valor nulo de horas trabalhadas assume um índice de utilidade negativo e o 
valor positivo de horas trabalhadas assume um índice de utilidade de valor positivo.

Ademais, os termos de erros nas Equações (7) e (8) são supostos independentes e a distribuição normal bivariada destes termos de erros é reescrita da seguinte forma (Cameron; Trivedi, 2005):

$$
\left(\begin{array}{l}
e_{1} \\
e_{2}
\end{array}\right) \sim N\left[\left(\begin{array}{l}
0 \\
0
\end{array}\right),\left(\begin{array}{cc}
1 & 0 \\
0 & \sigma^{2}
\end{array}\right)\right]
$$

Nesse sentido, é possível verificar que no modelo double hurdle não há correlação entre os termos de erros das equações, logo, as decisões não são tomadas de forma simultânea, mas de forma sequencial (Mesquita et al., 2012). A vantagem do modelo de Cragg sobre o modelo tobit é que o double hurdle permite que as variáveis tenham efeitos diferentes sobre as decisões de participação e alocação de horas de trabalho.

Os mesmos regressores podem aparecer em ambas as partes do modelo, embora esta condição possa ser relaxada se há limitações de exclusão óbvias (Cameron; Trivedi, 2005). As Equações (7) e (8) são estimadas por máxima verossimilhança separadamente.

\section{Base de dados e tratamentos}

Os dados que foram utilizados no trabalho são oriundos da Pesquisa Nacional por Amostra de Domicílios (PNAD) de 2011 realizado pelo Instituto Brasileiro de Geografia e Estatística (IBGE).

Optou-se pelo estudo da participação das mulheres no mercado de trabalho devido ao aumento da participação destas na força de trabalho brasileira nas últimas décadas. Para tanto, foram feitos recortes na amostra para manter somente as mulheres com idade entre $16 \mathrm{e}$ 80 anos. A idade mínima se sustenta na definição legal que estabelece a idade mínima de 16 anos para filiação do trabalhador ao Regime Geral de Previdência Social (RGPS), enquanto que a idade máxima está relacionada à baixa taxa de atividade nessa fase de vida. 
Quanto às variáveis explicativas dos modelos foram incluídas dummies para captar a influência do matrimônio e filhos menores sobre a oferta de trabalho feminina: casada com filhos, casada sem filhos, solteira com filhos e solteira sem filhos. Para controlar o papel da mulher como provedora do domicílio foi gerada uma variável de chefe de família. Para observar a influência da idade e o período de maternidade da mulher, bem como cuidados com crianças pequenas sobre o tempo dedicado ao trabalho não remunerado, foram acrescentadas dummies de interação entre faixas de idade da mulher ${ }^{6} \mathrm{e}$ crianças pequenas. ${ }^{7}$

Ainda com intenção de controlar a necessidade de maior tempo dedicado ao trabalho não remunerado pela mulher (trabalho doméstico) e cuidados com crianças menores foi incluída uma variável de interação entre horas dedicadas aos afazeres domésticos e filhos pequenos no domicílio. Também para controlar esses efeitos e a capacidade financeira de custear o cuidado dos filhos por terceiros, ${ }^{8}$ foi gerada uma variável de proporção de crianças matriculadas em creches, maternal/jardim de infância ou alfabetização no domicílio. ${ }^{9}$

Outras variáveis explicativas foram adicionadas aos modelos para controlar caraterísticas individuais e de capital humano: raça (branca), escolaridade ${ }^{10}$ e idade ao quadrado. Para captar o status socioeconômico da família na decisão de trabalho das mulheres, foram incluídas variáveis explicativas relacionadas às características de ocupação do cônjuge (trabalho com carteira assinada, sem carteira assinada, autônomo, empregador e funcionário público) e a renda total do esposo. Variáveis de localização também foram adicionadas, tais como moradia em área metropolitana, setor de residência (urbano/ rural) e regiões de moradia. A escolha das variáveis está conforme a literatura pertinente. Para uma descrição mais detalhada destas variáveis, sugere-se conferir o Quadro A.l em Apêndice.

Para a identificação dos modelos propostos, procedeu-se com o método de restrição por exclusão de variáveis proposto por Maddala

6 Faixas de idade da mulher: 16 a 20 anos, 21 a 30 anos, 31 a 40 anos, 41 ou mais anos.

7 Faixa de idade da criança: de 0 a 5 anos e de 6 a 10 anos.

8 A lei de diretrizes e bases da educação nacional (BRASIL. Lei n. 9.394, 20 de dezembro de 1996) define que crianças de até 5 anos de idade têm direito a creche e pré-escola públicos.

9 Desse modo busca-se minimizar o problema da endogeneidade que pode surgir da maior propensão das mulheres colocarem crianças em creches devido a necessidade de trabalhar.

10 Graus de instrução: menos de 1 anos de estudo, 1 a 4 anos de estudo, 5 a 8 anos de estudo, 9 a 10 anos de estudo e 12 anos ou mais de estudo. 
(1983). A partir desse método são excluídas algumas variáveis da equação de horas de trabalho e incluídas na equação de seleção a fim de identificar o modelo. A variável que entrou apenas na equação de participação no mercado de trabalho (seleção) foi total de moradores no domicílio, sendo excluída da equação de alocação de horas de trabalho. Assim, evita-se que essa variável esteja relacionada com o termo de erro do modelo de alocação de horas de trabalho. A partir da Tabela A.l, em apêndice, é possível conferir a amostra que após os filtros mencionados e a exclusão dos valores missing foi de 136.756 observações.

A idade média da mulher é de 40,6 anos, já a idade média daquelas que possuem filhos com idade entre 0 e 5 anos e 6 e 10 anos é de 31,7 e 34,2 anos, respectivamente. A grande maioria das mulheres possui 9 a 11 anos de estudo (34,3\%). Também verificou-se que pouco mais de $8 \%$ das mulheres têm idade entre 21 e 30 anos e crianças de 0 a 5 anos de idade, enquanto que $7 \%$ têm idade entre 31 a 40 anos e crianças entre 6 a 10 anos. Cerca de 53\% das mulheres é casada com filhos e pouco mais de $20 \%$ são solteiras e com filhos. A proporção de crianças do domicílio matriculadas em creches, jardim de infância ou alfabetização é pouco mais de $8 \%$. A renda do não trabalho da mulher é em média de $\mathrm{R} \$ 210,08$ e as horas médias trabalhadas por semana é de $18,8 \mathrm{~h}$, enquanto que as horas médias de trabalho doméstico para aquelas com crianças é de 10,4hr. As mulheres são maioria no meio urbano (87\%), em áreas não metropolitanas (67\%) e nas regiões Sudeste (44\%) e Nordeste (27\%). Em relação às características do cônjuge, grande parte das mulheres têm esposo com carteira de trabalho assinada (20\%) e a renda média total do esposo é cerca de $\mathrm{R} \$ 924,73$.

\section{Resultados}

Os resultados dos modelos heckit por máxima verossimilhança (MV) são apresentados na Tabela 3 e o resultado do modelo double hurdle pode ser conferido na Tabela A.2 em apêndice.

Em termos gerais, ambos os modelos captaram os mesmos sinais para as variáveis que foram estatisticamente significativas e assimetria de sinais para algumas variáveis. 
Os resultados gerados pelo modelo heckit e apresentados na Tabela 3 permitem ver que uma mulher branca tem menos probabilidade de ofertar trabalho do que uma não branca (omitida) e, com relação às horas de trabalho, a mulher branca dedica mais horas de trabalho do que a não branca.

A idade, que reflete a experiência no mercado de trabalho, apresentou efeito positivo sobre a chance de a mulher ofertar trabalho. Já a idade ao quadrado, que representa o efeito do crescimento não linear da produtividade, exibiu sinal negativo sobre a probabilidade de trabalhar. Logo, o efeito total da idade indica que a participação da mulher no mercado de trabalho aumenta a taxas decrescentes. Leme e Wajnman (1999) e Scorzafave e Menezes-Filho (2001) salientaram a importância da idade na decisão de oferta de trabalho feminina e encontraram resultados similares.

Quanto às variáveis de faixas de idade e filho pequeno, constatouse que as mulheres de todas as faixas de idade com filhos pequenos trabalham mais horas quando comparadas à categoria omitida (41 anos ou mais) (colunas 2 e 4). Note-se que há um aumento acentuado sobre as horas trabalhadas na faixa de 21 a 30 anos e redução significativa na jornada de trabalho na faixa de 31 a 40 anos, sobretudo, para aquelas com filhos entre 0 e 5 anos (coluna 2). Uma vez que a idade média das mulheres com filhos entre 0 e 5 anos é de 32 anos, ${ }^{11}$ pode-se sugerir que o período de maternidade e construção da família afetam a jornada de trabalho das mulheres devido aos maiores cuidados que requerem as crianças pequenas. Gonzaga et al. (2003) também apontaram que a jornada de trabalho tende a ser menor nesse período para depois se elevar e reduzir com a velhice. Esses resultados estão em consonância com os efeitos da maternidade sobre a oferta de trabalho da mulher ressaltados por Sedlacek e Santos (1991), Gonzaga et al. (2003) e Ramos et al. (2011).

No tocante à educação, percebe-se que à medida que a instrução aumenta, a probabilidade de a mulher trabalhar se eleva, se comparada à categoria omitida sem instrução. As horas de trabalho aumentam para as mulheres com 5 a 8 anos e 9 a 11 anos de estudo, e diminuem para aquelas que possuem 12 anos ou mais de estudo. De acordo com Mulligan e Rubinstein (2008), a elevada desigualdade de salários por gênero e entre as mulheres no mercado de trabalho

${ }^{11}$ Consultar a descrição da amostra na Tabela A.1 em apêndice. 
pode estimulá-las a investir em sua produtividade através do aumento da qualificação, favorecendo a absorção das mais hábeis pelo mercado de trabalho. Todavia, maior qualificação reflete em maior rendimento, consequentemente, a mulher mais qualificada tende a preferir mais horas de lazer ao invés de mais horas de trabalho devido ao aumento do efeito renda relativamente ao efeito substituição (Mincer, 1962; Aguiar; Hurst, 2006).

Quanto à condição da mulher na família, é possível observar que a mulher chefe de família tem mais chance de participar do mercado de trabalho, resultado que reforça o papel da renda do trabalho da mulher para o sustento do lar (Sedlacek; Santos, 1991). Ser casada com ou sem filhos, bem como ser solteira com filhos, reduz a possibilidade de a mulher trabalhar quando se compara com solteira sem filhos (categoria de referência). Chama-se atenção que a redução da chance de trabalho foi significativamente maior para as casadas, sugerindo que as mulheres tendem a reduzir sua participação no mercado de trabalho depois de casadas. Não obstante, percebeu-se um efeito um pouco maior na redução da chance de trabalho da casada com filho, principalmente nas horas de trabalho (coluna 4), cuja variável foi estatisticamente significativa. Estudos como o de Kreps (1971), Sedlacek e Santos (1991), Ramos et al. (2011) e Scorzafave e Menezes Filho (2005) também destacaram resultado negativo na participação da mulher cônjuge no mercado de trabalho, em especial quando a mulher possui filhos.

$\mathrm{Na}$ intenção de fornecer mais informações sobre a necessidade de horas dedicadas ao cuidado com filhos foi introduzida a variável de interação entre horas dedicadas aos afazeres domésticos e filhos pequenos. Esta variável se mostrou negativamente relacionada tanto com a participação da mulher na força de trabalho quanto com as horas de trabalho. A mulher pode preferir mais horas de trabalho doméstico não remunerado ao invés de horas de trabalho remunerado devido ao tempo demandando pelos cuidados com os filhos pequenos e em idade pré-escolar, como ressaltado por Martins (2001), Birch (2005), Aguiar e Hurst (2007) e Ramos et al. (2011). Portanto, esses resultados sugerem que as mulheres com filhos possuem um salário de reserva maior do que as que não possuem filhos, pois exigem maior retribuição salarial para compensar a redução de tempo dedicado aos filhos (Becker, 1991; Costa, 2007). 
Tabela 3 - Brasil: Modelo heckit por máxima verossimilhança (2011)

\begin{tabular}{|c|c|c|c|c|}
\hline \multirow[b]{2}{*}{ Variáveis } & \multicolumn{2}{|c|}{ Modelo 1} & \multicolumn{2}{|c|}{ Modelo 2} \\
\hline & $\begin{array}{c}(1) \\
\text { Probit }\end{array}$ & $\begin{array}{c}(2) \\
\text { Tobit }\end{array}$ & $\begin{array}{c}(3) \\
\text { Probit }\end{array}$ & $\begin{array}{c}\text { (4) } \\
\text { Tobit }\end{array}$ \\
\hline Raça & $\begin{array}{c}-0,0454^{* * *} \\
(0,0081)\end{array}$ & $\begin{array}{l}0,5453^{* \star *} \\
(0,1118)\end{array}$ & $\begin{array}{l}-0,0454^{* * *} \\
(0,0081)\end{array}$ & $\begin{array}{l}0,5395^{\star * *} \\
(0,1115)\end{array}$ \\
\hline Idade & $\begin{array}{l}0,1358^{* * *} \\
(0,0016)\end{array}$ & & $\begin{array}{l}0,1355^{\star * *} \\
(0,0016)\end{array}$ & \\
\hline Idade ao quadrado & $\begin{array}{c}-0,0017^{\star \star *} \\
(0,0000)\end{array}$ & & $\begin{array}{c}-0,0017^{\star \star *} \\
(0,0000)\end{array}$ & \\
\hline $\begin{array}{l}\text { Faixa de idade e filho de } 0 \text { a } 5 \\
\text { anos }\end{array}$ & & & & \\
\hline 16 a 20 anos & & $\begin{array}{l}1,0997^{\star *} \\
(0,4505)\end{array}$ & & \\
\hline 21 a 30 anos & & $\begin{array}{l}1,4176^{* * *} \\
(0,2061)\end{array}$ & & \\
\hline 31 a 40 anos & & $\begin{array}{c}0,7024^{* * *} \\
(0,2215)\end{array}$ & & \\
\hline $\begin{array}{l}\text { Faixa de idade e filho de } 6 \text { a } 10 \\
\text { anos }\end{array}$ & & & & \\
\hline 16 a 20 anos & & & & $\begin{array}{l}-0,6605 \\
(0,5226)\end{array}$ \\
\hline 21 a 30 anos & & & & $\begin{array}{l}1,8968^{* * *} \\
(0,2252)\end{array}$ \\
\hline 31 a 40 anos & & & & $\begin{array}{l}1,2257^{\star * *} \\
(0,1950)\end{array}$ \\
\hline Anos de & & & & \\
\hline 1 a 4 ano & $\begin{array}{c}0,1057^{* * *} \\
(0,0153)\end{array}$ & $\begin{array}{l}-0,3516 \\
(0,2831)\end{array}$ & $\begin{array}{c}0,1056^{\star * *} \\
(0,0153)\end{array}$ & $\begin{array}{l}-0,3275 \\
(0,2824)\end{array}$ \\
\hline 5 a 8 anos & $\begin{array}{c}0,2292^{* \star *} \\
(0,0145)\end{array}$ & $\begin{array}{c}0,9784^{\star \star *} \\
(0,2635)\end{array}$ & $\begin{array}{c}0,2294^{* * *} \\
(0,0145)\end{array}$ & $\begin{array}{c}1,0580^{* * *} \\
(0,2622)\end{array}$ \\
\hline 9 a 11 anos & $\begin{array}{c}0,4866^{* * *} \\
(0,0142)\end{array}$ & $\begin{array}{c}1,4557^{* * *} \\
(0,2562)\end{array}$ & $\begin{array}{c}0,4875^{\star \star *} \\
(0,0142)\end{array}$ & $\begin{array}{c}1,6389^{* * *} \\
(0,2539)\end{array}$ \\
\hline 12 anos ou mais & $\begin{array}{c}0,8863^{* * *} \\
(0,0165)\end{array}$ & $\begin{array}{c}-2,2950^{\star * *} \\
(0,2880)\end{array}$ & $\begin{array}{c}0,8884^{* \star *} \\
(0,0165)\end{array}$ & $\begin{array}{c}-2,0440^{* * *} \\
(0,2851)\end{array}$ \\
\hline Característi & & & & \\
\hline Chefe de família & $\begin{array}{c}0,1689^{* * *} \\
(0,0099)\end{array}$ & $\begin{array}{l}-0,1435 \\
(0,1345)\end{array}$ & $\begin{array}{c}0,1688^{* * *} \\
(0,0099)\end{array}$ & $\begin{array}{l}-0,1339 \\
(0,1338)\end{array}$ \\
\hline Casada s/ filho & $\begin{array}{c}-0,2174^{\star \star *} \\
(0,0176)\end{array}$ & $\begin{array}{c}0,1550 \\
(0,2310)\end{array}$ & $\begin{array}{c}-0,2175^{\star \star \star} \\
(0,0176)\end{array}$ & $\begin{array}{c}0,1077 \\
(0,2304)\end{array}$ \\
\hline Casada c/ filho & $\begin{array}{c}-0,2401^{\star * *} \\
(0,0159)\end{array}$ & $\begin{array}{l}-0,3071 \\
(0,2033)\end{array}$ & $\begin{array}{c}-0,2400^{* \star *} \\
(0,0159)\end{array}$ & $\begin{array}{c}-0,4021^{\star *} \\
(0,2033)\end{array}$ \\
\hline Solteira c/ filho & $\begin{array}{c}-0,0417^{* * *} \\
(0,0153)\end{array}$ & $\begin{array}{l}-0,2159 \\
(0,1983)\end{array}$ & $\begin{array}{c}-0,0414^{* * *} \\
(0,0153)\end{array}$ & $\begin{array}{l}-0,2527 \\
(0,1981)\end{array}$ \\
\hline h. afazeres domésticos e filhos & $\begin{array}{l}-0,0154^{* * *} \\
(0,0002)\end{array}$ & $\begin{array}{l}-0,0795^{\star * *} \\
(0,0052)\end{array}$ & $\begin{array}{l}-0,0154^{* * *} \\
(0,0002)\end{array}$ & $\begin{array}{c}-0,0892^{* \star *} \\
(0,0054)\end{array}$ \\
\hline Proporção de crianças em creches & $\begin{array}{c}0,0038^{* * *} \\
(0,0001)\end{array}$ & $\begin{array}{l}0,0029^{\star *} \\
(0,0021)\end{array}$ & $\begin{array}{c}0,0038^{* * *} \\
(0,0001)\end{array}$ & $\begin{array}{c}0,0103^{* * *} \\
(0,0020)\end{array}$ \\
\hline Renda do não trabalho & $\begin{array}{c}-0,3094^{* * *} \\
(0,0172)\end{array}$ & $\begin{array}{c}-0,5849^{* * *} \\
(0,1874)\end{array}$ & $\begin{array}{c}-0,3103^{\star * *} \\
(0,0172)\end{array}$ & $\begin{array}{c}-0,7066^{\star * *} \\
(0,1887)\end{array}$ \\
\hline Carac & & & & \\
\hline Renda total do esposo & $\begin{array}{c}-0,0114^{* * *} \\
(0,0023)\end{array}$ & $\begin{array}{c}0,0036 \\
(0,0246)\end{array}$ & $\begin{array}{c}-0,0114^{\star * *} \\
(0,0023)\end{array}$ & $\begin{array}{c}0,0017 \\
(0,0245)\end{array}$ \\
\hline Sem carteira & $\begin{array}{l}0,0356^{\star \star} \\
(0,0147)\end{array}$ & $\begin{array}{c}-1,2663^{* * *} \\
(0,2230)\end{array}$ & $\begin{array}{l}0,0357^{* *} \\
(0,0147)\end{array}$ & $\begin{array}{c}-1,2494^{* * *} \\
(0,2222)\end{array}$ \\
\hline Autônomo & $\begin{array}{c}0,1978^{\star \star *} \\
(0,0113)\end{array}$ & $\begin{array}{c}-0,9707^{* * *} \\
(0,1669)\end{array}$ & $\begin{array}{c}0,1978^{\star * *} \\
(0,0113)\end{array}$ & $\begin{array}{c}-0,9372^{* * *} \\
(0,1661)\end{array}$ \\
\hline Empregador & $\begin{array}{c}0,2979^{* * *} \\
(0,0256)\end{array}$ & $\begin{array}{l}0,7986^{* *} \\
(0,3171)\end{array}$ & $\begin{array}{c}0,2979^{* * *} \\
(0,0256)\end{array}$ & $\begin{array}{c}0,8347^{* * *} \\
(0,3158)\end{array}$ \\
\hline Funcionário público & $\begin{array}{c}0,0220 \\
(0,0217)\end{array}$ & $\begin{array}{c}-0,9670^{* \star *} \\
(0,2695)\end{array}$ & $\begin{array}{c}0,0223 \\
(0,0217)\end{array}$ & $\begin{array}{c}-0,9541^{* * *} \\
(0,2685)\end{array}$ \\
\hline
\end{tabular}


Tabela 3 - Brasil: Modelo heckit por máxima verossimilhança (2011) (Cont.)

\begin{tabular}{|c|c|c|c|c|}
\hline \multirow[b]{2}{*}{ Variáveis } & \multicolumn{2}{|c|}{ Modelo 1} & \multicolumn{2}{|c|}{ Modelo 2} \\
\hline & $\begin{array}{c}(1) \\
\text { Probit }\end{array}$ & $\begin{array}{c}(2) \\
\text { Tobit }\end{array}$ & $\begin{array}{c}(3) \\
\text { Probit }\end{array}$ & $\begin{array}{c}(4) \\
\text { Tobit }\end{array}$ \\
\hline Localização da moradia & & & & \\
\hline Região metropolitana & $\begin{array}{l}-0,0097 \\
(0,0080)\end{array}$ & $\begin{array}{l}1,0706^{* * *} \\
(0,1085)\end{array}$ & $\begin{array}{l}-0,0097 \\
(0,0080)\end{array}$ & $\begin{array}{c}1,0639^{* * *} \\
(0,1081)\end{array}$ \\
\hline Urbano & $\begin{array}{c}-0,1496^{* * *} \\
(0,0124)\end{array}$ & $\begin{array}{c}5,4777^{\star * *} \\
(0,2007)\end{array}$ & $\begin{array}{c}-0,1497^{\star * *} \\
(0,0124)\end{array}$ & $\begin{array}{c}5,4211^{* * *} \\
(0,1999)\end{array}$ \\
\hline Nordeste & $\begin{array}{c}-0,1570^{* * *} \\
(0,0099)\end{array}$ & $\begin{array}{c}-1,3148^{* * *} \\
(0,1427)\end{array}$ & $\begin{array}{c}-0,1572^{* * *} \\
(0,0099)\end{array}$ & $\begin{array}{c}-1,3411^{* * *} \\
(0,1422)\end{array}$ \\
\hline Sul & $\begin{array}{c}0,1322^{* * *} \\
(0,0116)\end{array}$ & $\begin{array}{c}0,2382 \\
(0,1531)\end{array}$ & $\begin{array}{c}0,1323^{* * *} \\
(0,0116)\end{array}$ & $\begin{array}{c}0,2739^{*} \\
(0,1525)\end{array}$ \\
\hline Centro Oeste & $\begin{array}{l}-0,0248^{*} \\
(0,0133)\end{array}$ & $\begin{array}{c}0,1771 \\
(0,1716)\end{array}$ & $\begin{array}{l}-0,0245^{\star} \\
(0,0133)\end{array}$ & $\begin{array}{c}0,1808 \\
(0,1711)\end{array}$ \\
\hline Norte & $\begin{array}{c}-0,1408^{* * *} \\
(0,0123)\end{array}$ & $\begin{array}{c}-0,6015^{* * *} \\
(0,1778)\end{array}$ & $\begin{array}{c}-0,1409^{* * *} \\
(0,0123)\end{array}$ & $\begin{array}{c}-0,6186^{* * *} \\
(0,1772)\end{array}$ \\
\hline Identificação do modelo & & & & \\
\hline Total de moradores & $\begin{array}{c}-0,0296^{* * *} \\
(0,0071)\end{array}$ & & $\begin{array}{c}-0,0299^{* * *} \\
(0,0072)\end{array}$ & \\
\hline$\rho$ & & $\begin{array}{c}-0,3537^{* * *} \\
(0,0206)\end{array}$ & & $\begin{array}{c}-0,3416^{\star * *} \\
(0,0201)\end{array}$ \\
\hline$\sigma$ & & $\begin{array}{c}13,4433^{\star \star *} \\
(0,0048)\end{array}$ & & $\begin{array}{c}2,5930^{* * *} \\
(0,0046)\end{array}$ \\
\hline Constante & $\begin{array}{c}-2,1691^{* * *} \\
(0,0357)\end{array}$ & $\begin{array}{c}35,6359^{* * *} \\
(0,4043)\end{array}$ & $\begin{array}{c}-2,1654^{* * *} \\
(0,0358)\end{array}$ & $\begin{array}{c}35,3556^{\star \star *} \\
(0,3999)\end{array}$ \\
\hline Teste de Wald & & $320,87^{* * *}$ & & $290,28^{\star * *}$ \\
\hline Critério AIC & & $692.766,6$ & & $692.719,8$ \\
\hline Critério BIC & & $693.316,9$ & & $693.270,0$ \\
\hline Observações & & 136.756 & & 136.756 \\
\hline
\end{tabular}

Fonte: Elaborado pelos autores a partir de dados da PNAD de 2011.

Nota: Desvios-padrões robustos à heterocedasticidade entre parênteses. * estatisticamente significativo a $10 \%$; ${ }^{* *}$ estatisticamente significativo a $5 \%$; ${ }^{* *}$ estatisticamente significativo a $1 \%$.

Quanto à variável proporção de crianças matriculadas em creches (inclui também maternal, jardim de infância e alfabetização) no domicílio, verificou-se sinal positivo tanto para a oferta de trabalho da mulher quanto para as horas de trabalho. Assim, a mãe com filhos menores tende a participar mais do mercado de trabalho quando tem acesso a creches para substituir o tempo que ela dedicaria no cuidado dos filhos. Esse resultado destaca a importância das creches para aumentar a participação feminina na força de trabalho, principalmente das mães mais pobres que não podem suportar os custos financeiros desse serviço. Esse resultado está em acordo com os argumentos de Ramos et al. (2011) e Costa (2007).

A renda do não trabalho da mulher apresentou sinal negativo tanto para oferta de trabalho quanto para a alocação de tempo em traba1ho. Desse modo, as mulheres que dispõem de rendimento do não 
trabalho, como pensões e aposentadorias, podem preferir mais horas de lazer devido ao efeito renda (Mincer, 1962). Hoffmann e Leone (2004) destacaram que houve um crescimento considerável dessas outras rendas da mulher na composição do rendimento domiciliar como resultado da maior participação feminina no mercado de trabalho ao longo dos anos.

O total de moradores no domicílio reduz a oferta de trabalho das mulheres. Esse resultado pode estar sugerindo a necessidade de cuidado dos moradores por parte da mulher ou pode estar indicando a contribuição da renda dessas pessoas para o rendimento domiciliar que tende a aumentar o salário reserva da mulher e reduzir a chance de trabalho feminino (Scorzafave; Menezes-Filho, 2001).

Em relação às características do esposo, constatou-se que a renda total deste foi estatisticamente significativa e negativa para a decisão de participação da mulher na força de trabalho. Assim sendo, uma redução na renda do marido pode ser definitiva para que a mulher ingresse na força de trabalho a fim de complementar o rendimento domiciliar. Esse resultado destaca o efeito do cônjuge na decisão de trabalho feminina e suporta o efeito do trabalhador adicional encontrado por Sedlacek e Santos (1991), Ramos e Soares (1995) e Schmitt e Ribeiro (2004).

Os resultados mais interessantes das variáveis de ocupação do esposo mostraram que a mulher, cujo esposo estava ocupado como empregador e autônomo, tem maior probabilidade de trabalhar, embora seja o primeiro tipo de ocupação que gera mais horas trabalhadas pela mulher quando se contrasta com a omitida (carteira assinada). Esse resultado pode estar indicando tanto a necessidade de complementação do rendimento domiciliar pela esposa, devido à maior insegurança envolvida nessas ocupações, quanto o engajamento no empreendimento do esposo para colaborar para a sua prosperidade. ${ }^{12}$

Reportando-se à região de moradia, vê-se que as mulheres residentes em setor urbano têm menos chance de se inserirem no mercado de trabalho, embora trabalhem mais horas quando comparadas com a categoria omitida (setor rural). As moradoras de áreas metropolitanas também trabalham mais horas. As mulheres residentes da

12 Normalmente nas ocupações como empregador e autônomo, o rendimento auferido depende do desempenho e da dedicação do trabalhador, fato que pode contribuir para o engajamento do cônjuge na atividade. 
região Sul têm mais chance de ofertar trabalho do que as de outras regiões, relativamente à categoria base Sudeste. Por outro lado, as mulheres do Norte e Nordeste ofertam menos horas de trabalho do que as residentes do Sudeste. O elevado custo de vida das grandes cidades pode ser uma das explicações para as horas a mais dedicadas ao trabalho, como apontado por Aguiar e Hurst (2007), bem como a maior competitividade no mercado de trabalho. Não obstante, a presença de amenidades em grandes cidades pode ter efeito inverso e contribuir pela preferência por mais lazer, reduzindo as chances de trabalho das mulheres.

No modelo heckit, o $\rho$ representa o coeficiente de correlação entre os termos de erro da equação de seleção (participação no mercado de trabalho) e alocação de horas de trabalho. A partir dos resultados do modelo pode-se ver que o $\rho$ é estatisticamente significativo e o sinal negativo sugere seleção positiva das trabalhadoras em tributos produtivos não observados. Este resultado reforça a necessidade de considerar conjuntamente a probabilidade de participação no mercado de trabalho e alocação de horas trabalhadas.

Reportando-se aos resultados do modelo double hurdle na Tabela A.2 em Apêndice, verifica-se que os sinais e significância estatística das variáveis foram bem semelhantes aos resultados já discutidos para o modelo heckit, e que ambos os modelos conseguiram captar sinais distintos para as duas decisões. Todavia, cabe mencionar que a variável de anos de estudo (12 ou mais anos) apresentou sinal positivo indicando que essas mulheres têm chance de ofertar mais horas de trabalho do que aquelas sem instrução, embora o efeito tenha sido maior para 9 a 11 anos de estudo e 5 a 8 anos de estudo. Outro resultado que chamou atenção foi o da variável chefe de família, que apresentou sinal positivo para horas trabalhadas, sugerindo que elas têm que trabalhar mais para sustentar a família. As variáveis casadas com e sem filho foram estatisticamente significativas e negativas, indicando redução da jornada de trabalho.

Por fim, a moradia em área metropolitana foi estatisticamente significativa e negativa com relação à oferta de trabalho feminina. De acordo com esse resultado, são as mulheres que moram em regiões não metropolitanas que têm mais chance de ofertar trabalho. Como já discutido, a presença de amenidades nas grandes cidades, como 
mais opções de lazer, pode colaborar para esse resultado. Apesar de captar efeitos muito similares ao modelo heckit, os resultados do modelo double hurdle devem ser vistos com cautela, pois neste modelo a escolha de horas de trabalho não possui correlação com a decisão de participação das mulheres no mercado de trabalho.

Para decidir sobre o melhor modelo foi feito o teste LR (likelihood ratio test $)^{13}$ levando em consideração os resultados do modelo heckit (MV) e double hurdle. O resultado permitiu concluir que o modelo heckit (MV) é melhor ajustado que o modelo double hurdle para explicar a decisão de participação da mulher no mercado de trabalho e alocação de tempo em trabalho. ${ }^{14}$ Através dos critérios AIC e BIC também foi possível chegar à mesma conclusão, pois o heckit é o modelo que possui os menores critérios.

Dessa forma, este trabalho permitiu observar que a mulher se depara com limitações na participação no mercado de trabalho devido ao contexto familiar, como casamento, criação dos filhos e condição financeira. Mesmo após vários avanços socioculturais, a mulher enfrenta geralmente uma dupla jornada em casa e no trabalho. Além disso, a incapacidade financeira de arcar com os custos financeiros para o cuidado dos filhos pequenos por terceiros pode coibir a participação feminina no mercado de trabalho. Portanto, a elevação da educação feminina e ampliação do acesso a meios para o cuidado das crianças na primeira infância podem contribuir para aumentar a oferta de trabalho das mulheres.

\section{Conclusões}

Este trabalho teve por objetivo investigar a oferta de trabalho e alocação de tempo em trabalho pelas mulheres brasileiras usando dados da PNAD de 2011. As transformações econômicas e sociais que têm ocorrido contribuíram para aumentar a participação feminina na força de trabalho ao longo do tempo, chamando atenção para o papel

${ }^{13}$ Diante do conhecimento da fragilidade do teste LR para modelos com erros robustos à heterocedasticidade (Cameron e Trivedi, 2005), também foi feita a análise usando os critérios Akaike (AIC) e Schwarz (BIC).

${ }^{14}$ Estatística do modelo 1: : $L R \chi^{2}=30.791,15(0,0000)$ e do modelo 2: $L R \chi^{2}=30.713,97$ $(0,0000)$. 
do estudo, idade, casamento, maternidade e acesso a creches para a alocação de horas de trabalho. Os modelos propostos para modelar a participação feminina no mercado de trabalho e horas de trabalho foram um método heckit e outro chamado double hurdle. A vantagem deste último é permitir a influência das variáveis explicativas separadamente em cada decisão. Mesmo que os resultados sejam semelhantes, os testes feitos sugeriram que o modelo que melhor representa as decisões da mulher é o método heckit.

Os resultados mais importantes mostraram que a chance de oferta de trabalho feminina aumenta com a idade a taxas decrescentes, e que a alocação de tempo em trabalho daquelas com filhos pequenos é menor na faixa de 31 a 40 anos de idade, principalmente se a mulher possuir filho de até 5 anos de idade. Uma vez que as mulheres estão postergando a maternidade para além dos 30 anos de idade por motivos de estabilidade profissional e qualificação, esses resultados sugerem que a participação feminina no mercado de trabalho é influenciada pelo período de maternidade e construção da família.

O nível de educação, por sua vez, eleva a chance de trabalho e horas destinadas ao trabalho, embora as mulheres com nível superior trabalhem menos horas, resultado que pode estar relacionado com os rendimentos mais elevados que estas têm acesso e que lhes permitem comprar mais lazer.

Concluiu-se também que a mulheres chefes de família têm mais chance de trabalhar, apontando para o papel de provedora do lar, enquanto que as casadas registram menor propensão ao trabalho, resultado que sugere influência do matrimonio e reforça o papel da mulher como dona de casa. As horas dedicadas ao trabalho doméstico pelas mulheres com filhos pequenos reduzem tanto a chance de trabalho quanto o número de horas trabalhadas. Já a proporção de crianças matriculadas em creches eleva a probabilidade de inserção feminina no mercado de trabalho, bem como as horas trabalhadas. Logo, se a mulher tiver mais acesso a creches para substituir o tempo dedicado ao cuidado dos seus filhos pequenos, a tendência de ficar fora do mercado de trabalho se reverte em favor do trabalho.

A renda do não trabalho reduz a participação feminina na força de trabalho, destacando a importância de rendimentos como pensões, aposentadorias e outras transferências do governo nessa decisão. 
A renda do cônjuge, por sua vez, reduz tanto a chance de trabalho feminino quanto as horas trabalhadas, suportando a tese de que a mulher se engaja na força de trabalho para ajudar no rendimento domiciliar, enquanto que ter cônjuge ocupado como empregador eleva a propensão ao trabalho feminino, resultado que pode estar relacionado à necessidade de colaboração no empreendimento do esposo ou incerteza envolvida nesse tipo de ocupação.

Por fim, é possível inferir que a mulher sofre dificuldade em permanecer no mercado de trabalho devido ao seu ciclo de vida, como formação da família e maternidade. Esse período demanda tempo e dedicação da mulher, que tende a reduzir sua participação na força de trabalho para dedicar mais tempo a sua família. Neste sentido, as políticas públicas devem ser voltadas para aumentar a oferta de creches e o nível de escolaridade das mulheres para que estas possam aumentar sua participação no mercado de trabalho.

\section{Referências}

AGUIAR, M.; HURST, E. Measuring Trends in Leisure: The Allocation of Time over Five Decades. The Quarterly Journal of Economics, n.122, p. 969-1006, 2007.

BECKER, G. A treatise on the family. Harvard University Press, 1991.

BIRCH, ELISA-ROSE. Studies of the labour supply of Australian women: what have we learned? The Economic Record, v. 81, n. 252, mar, p. 65-84, 2005.

BORJAS, G. J. Labor Economics. New York: The McGraw-Hill Companies, 1996.

BRASIL. Lei n. 9.394, de 20 de dezembro de 1996. Estabelece as diretrizes e bases da educação nacional. Diário Oficial [da] República Federativa do Brasil, Poder Legislativo, Brasília, 20 dez. 1996.

CAMERON, A. C.; TRIVEDI, P. K. Microeconometrics: methods and applications. Cambridge University Press, 2005.

COSTA, J. Determinantes da participação feminina no mercado de trabalho brasileiro. Dissertação de Mestrado, Universidade de Brasília, 2007.

CIRINO, J. F.; LIMA, J. E. Determinantes da Participação Feminina no Mercado de Trabalho: uma Comparação entre os Sexos e entre os Mercados das Regiões Metropolitanas de Belo Horizonte e Salvador. Revista Econômica do Nordeste, Fortaleza, v. 42, n. 1, 2011.

FONTOURA, N. O.; GONZALEZ, R. Aumento da participação feminina no mercado de trabalho: mudança ou reprodução da desigualdade? In: Mercado de Trabalho, n.41, 2009.

GONZAGA, G.; MACHADO, A. F.; MACHADO, D. C. Horas de trabalho: efeitos idade, período e coorte. Texto para Discussão, Rio de Janeiro: Departamento de Economia PUC-Rio, n. 473, 2003.

CRAGG, J. Some Statistical Models for Limited Dependent Variables with Application to the Demand for Durable Goods. Econometrica, v. 39, n. 5, p. 829-844, 1971.

GRONAU, R. Leisure, Home Production and Work:The Theory of the Allocation of Time Revisited. Journal of Political Economy, n. 85, p. 1099-123, 1977.

Estud. Econ., São Paulo, vol.45, n.4, p.787-819, out.-dez. 2015 
HECKMAN, J. Effects of Childcare Programs on Women's Work Effort. Journal of Political Economy, n. 82, p.136-136, 1974.

HECKMAN, J. Sample Selection Bias as a Specification Error. Econometrica, n. 47, 153-161, 1979.

HOFFMANN, R.; LEONE, E. T. Participação da Mulher no Mercado de Trabalho e Desigualdade da Renda Domiciliar per Capita no Brasil: 1981-2002. Nova Economia, vol. 14, n. 2, p.35-58, 2004.

ILO (International Labor Organization). Key Indicators of the labour Market, 7th Edition, 2012.

KREPS, J. Sex in the market place: American women at work. Baltimore: The John Hopkins University, 1971.

KREPS, J.; CLARK, R. Sex, age and work: the changing composition of the labor force. Baltimore: The Johns Hopkins University, 1975.

LEME, M.; WAJNMAN, S. Efeitos do periodo, coorte e ciclo de vida na participação feminina no mercado de trabalho brasileiro. In: Anais do XXI Encontro Brasileiro de Econometria (SBE), Belém, 1999.

MADDALA, G. S. Models with self-selection. In: Limited-dependent and qualitative variables in Econometrics. Econometric Society Monographs. Cambridge: Cambridge University Press, 1983.

MARTINS, M. F. O. Parametric and semiparametric Estimation of sample selection Models: An Empirical Application to the female labour force in Portugal. Journal of Applied Econometrics, n. 6, p.23-39, 2001.

MESQUITA, S. P.; SAMPAIO, L. M. B.; RAMALHO, H. M. B. Fatores Determinantes da Alocação de Tempo em Trabalho Não-Agrícola por Famílias do Projeto Dom Helder Câmara. Revista Econômica do Nordeste. v. 43, n. 1, jan/mar, 2012.

MINCER, J. Labor force participation of married women: a study of labor supply. In: Aspects of Labor Economics, Princeton: National Bureau of Economic Research, 1962.

MINISTÉRIO DA PREVIDÊNCIA SOCIAL. Projeções atuariais para o regime geral de previdência social - RGPS. Secretaria de Políticas de Previdência Social. Brasília (DF), abril, 2011.

MROZ, T. The Sensitivity of an Empirical Model of Married Women's Hours of Work to Economic and Statistical Assumptions. Econometrica, n. 55, p.765-99, 1987.

MULLIGAN, C. B.; RUBINSTEIN, Y. Selection, investment, and women's relative wages over time. The Quarterly Journal of Economics, August, 2008.

RAMOS, L.; SOARES, A. L. Participação da Mulher na Força de Trabalho e Pobreza no Brasil. Revista de Economia Politica, São Paulo, v. 15, n. 3(59), p. 84-96, jul-set., 1995.

RAMOS, L.; AGUAS, M. F. F.; FURTADO, L. M. de S. Participação feminina na força de trabalho metropolitano: o papel do status socioeconômico das famílias. Economia Aplicada, v.15, n. 4, p. 595-611, 2011.

SCORZAFAVE, L. G.; MENEZES-FILHO, N. A. Participação feminina no mercado de trabalho brasileiro: Evolução e determinantes. Pesquisa e Planejamento Econômico, v. 31, n. 3, p. 441-478, 2001.

SCHMITT, C.; RIBEIRO, E. P. Participação feminina no mercado de trabalho e o efeito trabalhador adicional e Porto Alegre. Ensaios Fundação Economia e Estatística - FEE, v. 25, n.1, p. 145170, abr., 2004.

SEDLACEK, G. L.; SANTOS, E. C. A mulher cônjuge no Mercado de Trabalho como Estratégia de Geração de Renda Familiar. Texto para Discussão No 209, Rio de Janeiro: IPEA, 1991.

PSACHAROPOULOS, G.; TZANNATOS, Z. Women's employment and pay in Latin America: overview and methodology. The World Bank, Washington, 1992.

WAJNMAN, S.; RIOS-NETO, E. Quantas serão as mulheres: cenários para a atividade feminina. In: ROCHA, M. I. B. (Coord.). Trabalho e gênero: mudanças, permanências e desafios. ABEP, NEPO/UNICAMP e CEDEPLAR/UFMG, Editora 34, 2000. 


\section{Apêndice}

Quadro A.1 - Descrição das variáveis selecionadas

\begin{tabular}{|c|c|}
\hline Variáveis & Descrição \\
\hline Raça & 1 - branca; 0 - caso contrário* \\
\hline Idade & Idade em anos \\
\hline Idade ao quadrado & Idade ao quadrado \\
\hline $\begin{array}{l}\text { Faixas de idade e filho de } 0 \text { a } 5 \\
\text { anos }\end{array}$ & $\begin{array}{l}1-16 \text { a } 20 \text { anos e filho } 0 \text { a } 5 \text { anos } ; 2-21 \text { a } 30 \text { anos e filho } 0 \text { a } \\
5 \text { anos; } 3-31 \text { a } 40 \text { anos e filho } 0 \text { a } 5 \text { anos; } 4-41 \text { anos ou mais } \\
\text { e filho } 0 \text { a } 5 \text { anos }\end{array}$ \\
\hline $\begin{array}{l}\text { Faixas de idade e filho de } 6 \text { a } 10 \\
\text { anos }\end{array}$ & $\begin{array}{l}1-16 \text { a } 20 \text { anos e filho } 6 \text { a } 10 \text { anos }^{*} ; 2-21 \text { a } 30 \text { anos e filho } 6 \\
\text { a } 10 \text { anos; } 3-31 \text { a } 40 \text { anos e filho } 6 \text { a } 10 \text { anos; } 4-41 \text { anos ou } \\
\text { mais e filho } 6 \text { a } 10 \text { anos }\end{array}$ \\
\hline Escolaridade & $\begin{array}{l}1 \text { - sem instrução (menos de } 1 \text { ano de estudo); } 2 \text { - } 1 \text { a } 4 \text { anos } \\
\text { de estudo; } 3-5 \text { a } 8 \text { anos de estudo; } 4-9 \text { a } 11 \text { anos de estudo; } \\
5-11 \text { anos de estudo ou mais }\end{array}$ \\
\hline \multicolumn{2}{|l|}{ Característica de família e renda } \\
\hline Renda do não trabalho & $\begin{array}{l}\text { Renda oriunda de outras fontes em } \mathrm{R} \$ 2011 \text { (exclui a renda do } \\
\text { trabalho) }\end{array}$ \\
\hline Chefe de família & 1 - responsável pelo domicílio; 0 - caso contrário* \\
\hline Condição civil e filhos & $\begin{array}{l}1 \text { - casada sem filhos; } 2 \text { - casada com filhos; } 3 \text { - solteira com } \\
\text { filhos; } 4 \text { - solteira sem filhos* }\end{array}$ \\
\hline Proporção de crianças em creche & $\begin{array}{l}\text { Proporção de crianças } 0 \text { a } 10 \text { anos no domicílio que estavam ma- } \\
\text { triculadas em creche, maternal/jardim de infância e alfabetização }\end{array}$ \\
\hline $\begin{array}{l}\text { Horas de trabalho doméstico e } \\
\text { filho }\end{array}$ & $\begin{array}{l}\text { Horas dedicadas ao trabalho doméstico e possuir filho de } 0 \text { a } 10 \\
\text { anos }\end{array}$ \\
\hline Total de familiares & $\begin{array}{l}\text { Total de familiares no domicílio que inclui agregados, pensionistas } \\
\text { e outros familiares }\end{array}$ \\
\hline \multicolumn{2}{|l|}{ Características do esposo } \\
\hline Renda total do esposo & Renda total do esposo em R\$ de 2011 \\
\hline Ocupação do esposo & $\begin{array}{l}1 \text { - trabalho com carteira assinada*; } 2 \text { - trabalho sem carteira de } \\
\text { trabalho assinada; } 3 \text { - autônomo; } 4 \text { - empregador; } 5 \text { - funcionário } \\
\text { público }\end{array}$ \\
\hline \multicolumn{2}{|l|}{ Características de moradia } \\
\hline $\begin{array}{l}\text { Residência em região metropoli- } \\
\text { tana }\end{array}$ & 1 - reside em região metropolitana; 0 - caso contrário* \\
\hline Residência em área urbana & 1 - reside em área urbana; 0 - caso contrário* \\
\hline Região de moradia no país & 1 - Nordeste; 2 - Sul; 3 - Centro Oeste; 4 - Norte; 5 - Sudeste* \\
\hline
\end{tabular}

Fonte: Elaboração própria a partir dos dados da PNAD de 2011.

Nota: * categoria base. Para variáveis com mais de duas categorias, cada fator representa uma variável binária. 
Tabela A.1 - Brasil - Descrição estatística da amostra (2011)

\begin{tabular}{|c|c|c|}
\hline Variável & Média & Desvio padrão \\
\hline Branco & $49,9 \%$ & $50,0 \%$ \\
\hline Não branco* & $50,1 \%$ & $50,0 \%$ \\
\hline \multicolumn{3}{|l|}{ Anos de estudo } \\
\hline Menos de 1 ano* & $11,9 \%$ & $32,3 \%$ \\
\hline 1 a 4 anos & $16,6 \%$ & $37,2 \%$ \\
\hline 5 a 8 anos & $20,7 \%$ & $40,5 \%$ \\
\hline 9 a 11 anos & $34,3 \%$ & $47,5 \%$ \\
\hline 12 anos ou mais & $16,6 \%$ & $37,2 \%$ \\
\hline \multicolumn{3}{|l|}{ Faixa de idade e filho 0 a 5 anos } \\
\hline 16 a 20 anos & $2,3 \%$ & $15,1 \%$ \\
\hline 21 a 30 anos & $8,4 \%$ & $27,7 \%$ \\
\hline 31 a 40 anos & $6,0 \%$ & $23,7 \%$ \\
\hline 41 anos ou mais* & $3,3 \%$ & $17,9 \%$ \\
\hline \multicolumn{3}{|l|}{ Faixa de idade e filho 6 a 10 anos } \\
\hline 16 a 20 anos & $1,6 \%$ & $12,6 \%$ \\
\hline 21 a 30 anos & $5,5 \%$ & $22,7 \%$ \\
\hline 31 a 40 anos & $7,1 \%$ & $25,7 \%$ \\
\hline 41 anos ou mais* & $4,2 \%$ & $20,0 \%$ \\
\hline \multicolumn{3}{|l|}{ Características familiares } \\
\hline Chefe de família & $31,1 \%$ & $46,3 \%$ \\
\hline Não chefe de família* & $68,9 \%$ & $46,3 \%$ \\
\hline Casada sem filho & $16,3 \%$ & $36,9 \%$ \\
\hline Casada com filho & $52,8 \%$ & $49,9 \%$ \\
\hline Solteira com filho & $20,4 \%$ & $40,3 \%$ \\
\hline Solteira sem filho* & $10,5 \%$ & $30,6 \%$ \\
\hline \multicolumn{2}{|l|}{ Características de ocupação esposo } & $25,6 \%$ \\
\hline Com carteira assinada* & $20,2 \%$ & $40,2 \%$ \\
\hline Sem carteira assinada & $7,1 \%$ & $25,6 \%$ \\
\hline Autônomo & $15,7 \%$ & $36,4 \%$ \\
\hline Empregador & $2,7 \%$ & $16,1 \%$ \\
\hline Funcionário público & $2,8 \%$ & $16,6 \%$ \\
\hline \multicolumn{3}{|l|}{ Localização da residência } \\
\hline Urbano & $87,1 \%$ & $33,5 \%$ \\
\hline Não urbano* & $12,9 \%$ & $33,5 \%$ \\
\hline Área metropolitana & $32,7 \%$ & $46,9 \%$ \\
\hline Área não metropolitana* & $67,3 \%$ & $46,9 \%$ \\
\hline Nordeste & $26,9 \%$ & $44,3 \%$ \\
\hline Sul & $14,6 \%$ & $35,3 \%$ \\
\hline Centro Oeste & $7,4 \%$ & $26,2 \%$ \\
\hline Norte & $7,5 \%$ & $26,3 \%$ \\
\hline Sudeste* & $43,6 \%$ & $49,6 \%$ \\
\hline \multicolumn{3}{|l|}{ Média } \\
\hline Idade da mulher & 40,6 & 16,4 \\
\hline Idade da mulher com filho 0 a 5 anos & 31,7 & 11,2 \\
\hline Idade da mulher com filho 6 a 10 anos & 34,2 & 10,9 \\
\hline Renda do não trabalho $(\mathrm{R} \$)$ & 210,08 & 648,86 \\
\hline Renda total do esposo ( $R \$)$ & 924,73 & $2.270,52$ \\
\hline Total de moradores do domicílio & 0,2 & 0,5 \\
\hline Horas de trabalho na semana & 18,8 & 20,7 \\
\hline Hora de afazeres domésticos e filho & 10,4 & 17,8 \\
\hline
\end{tabular}

Fonte: Elaboração própria a partir de dados da PNAD de 2011,

Notas: * Categoria de referência em variável qualitativa, 
Tabela A.2 - Brasil: Modelo double hurdle (2011)

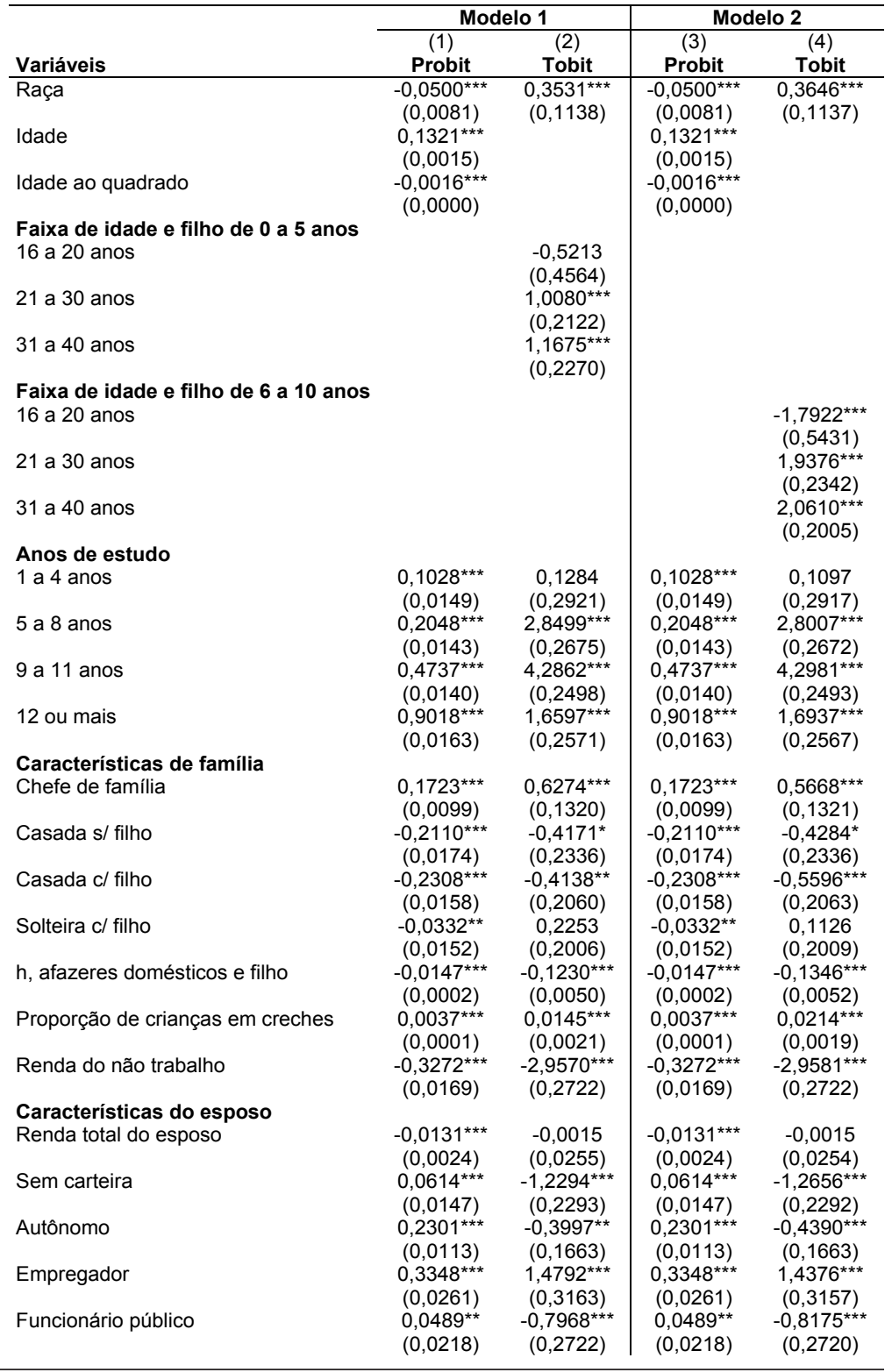


Tabela A.2 - Brasil: Modelo double hurdle (2011) (Continuação)

\begin{tabular}{|c|c|c|c|c|}
\hline \multirow[b]{2}{*}{ Variáveis } & \multicolumn{2}{|c|}{ Modelo 1} & \multicolumn{2}{|c|}{ Modelo 2} \\
\hline & $\begin{array}{c}(1) \\
\text { Probit }\end{array}$ & $\begin{array}{c}(2) \\
\text { Tobit }\end{array}$ & $\begin{array}{c}(3) \\
\text { Probit }\end{array}$ & $\begin{array}{c}(4) \\
\text { Tobit }\end{array}$ \\
\hline \multicolumn{5}{|l|}{ Localização da moradia } \\
\hline Região metropolitana & $\begin{array}{c}-0,0364^{\star * *} \\
(0,0080)\end{array}$ & $\begin{array}{c}1,2856^{\star * *} \\
(0,1098)\end{array}$ & $\begin{array}{c}-0,0364^{\star * *} \\
(0,0080)\end{array}$ & $\begin{array}{c}1,2902^{* * *} \\
(0,1097)\end{array}$ \\
\hline Urbano & $\begin{array}{c}-0,3457^{\star * *} \\
(0,0125)\end{array}$ & $\begin{array}{c}7,3686^{* * *} \\
(0,2120)\end{array}$ & $\begin{array}{c}-0,3457^{* * *} \\
(0,0125)\end{array}$ & $\begin{array}{c}7,3420^{* * *} \\
(0,2115)\end{array}$ \\
\hline Nordeste & $\begin{array}{c}-0,1719^{* \star *} \\
(0,0099)\end{array}$ & $\begin{array}{c}-1,7897^{\star * *} \\
(0,1439)\end{array}$ & $\begin{array}{c}-0,1719^{* * *} \\
(0,0099)\end{array}$ & $\begin{array}{c}-1,7841^{* * *} \\
(0,1438)\end{array}$ \\
\hline Sul & $\begin{array}{c}0,1659^{\star \star \star *} \\
(0,0116)\end{array}$ & $\begin{array}{c}0,5545^{\star * *} \\
(0,1539)\end{array}$ & $\begin{array}{c}0,1659^{* * *} \\
(0,0116)\end{array}$ & $\begin{array}{c}0,5677^{\star * *} \\
(0,1537)\end{array}$ \\
\hline Centro Oeste & $\begin{array}{l}-0,0175 \\
(0,0133)\end{array}$ & $\begin{array}{c}0,1538 \\
(0,1733)\end{array}$ & $\begin{array}{l}-0,0175 \\
(0,0133)\end{array}$ & $\begin{array}{c}0,1502 \\
(0,1731)\end{array}$ \\
\hline Norte & $\begin{array}{c}-0,1373^{* * *} \\
(0,0123)\end{array}$ & $\begin{array}{c}-1,2140^{\star * \star} \\
(0,1803)\end{array}$ & $\begin{array}{c}-0,1373^{* * *} \\
(0,0123)\end{array}$ & $\begin{array}{c}-1,2229^{* * *} \\
(0,1801)\end{array}$ \\
\hline Identificação do modelo & & & & \\
\hline Total de moradores do domicílio & $\begin{array}{c}-0,0392^{* * *} \\
(0,0072)\end{array}$ & & $\begin{array}{c}-0,0392^{\star * *} \\
(0,0072)\end{array}$ & \\
\hline$\sigma$ & & $\begin{array}{c}13,5093^{* * *} \\
(0,0528)\end{array}$ & & $\begin{array}{c}13,4973^{\text {*** }} \\
(0,0529)\end{array}$ \\
\hline Intercepto & $\begin{array}{c}-1,9103^{* * *} \\
(0,0352)\end{array}$ & $\begin{array}{c}28,0268^{* * *} \\
(0,3558)\end{array}$ & $\begin{array}{c}-1,9103^{\text {***}} \\
(0,0352)\end{array}$ & $\begin{array}{c}28,0933^{* * *} \\
(0,3554)\end{array}$ \\
\hline $\begin{array}{l}\text { Critério AIC } \\
\text { Critério BIC } \\
\text { Observações }\end{array}$ & $\begin{array}{c}723.555,8 \\
724.096,2 \\
\mathbf{1 3 6 . 7 5 6}\end{array}$ & & $\begin{array}{c}723.431,8 \\
723.972,2 \\
136.756\end{array}$ & \\
\hline
\end{tabular}

